\title{
GREEN GELLED PROPELLANT HIGHLY THROTTEABLE ROCKET MOTOR AND GAS GENERATOR TECHNOLOGY: STATUS AND APPLICATION
}

\author{
P. Caldas Pinto ${ }^{1}$, H. K. Ciezki ${ }^{2}$, K. W. Naumann ${ }^{1}$, \\ J. Ramsel ${ }^{1}$, P. Kröger ${ }^{2}$, H. Niedermaier ${ }^{1}$, M. Negri ${ }^{2}$, \\ S. Scheutzow ${ }^{1}$, A. Thumann ${ }^{1}$, and G. Kurth ${ }^{1}$ \\ ${ }^{1}$ Bayern-Chemie GmbH \\ P.O. Box 1131, Aschau am Inn 84544, Germany \\ ${ }^{2}$ DLR Institute of Space Propulsion \\ Lampoldshausen, Langer Grund, Hardthausen 74239, Germany
}

\begin{abstract}
Work on gel propulsion began in Germany in 1999. The German Gel Propulsion Technology (GGPT) Program started in 2001 from a white sheet of paper, proposed by the DLR Institute of Space Propulsion, Bayern-Chemie (BC), and the Fraunhofer Institute of Chemical Technology. Aim of the first phase was to develop the technology needed to build a rocket motor burning gelled propellants and to demonstrate its operability by a free flight within significantly less than a decade. The research and development activities were guided by a suitable principal concept for a gelled propellant rocket motor (GRM). Based on theoretical considerations (regarding functional aspects) and experimental pre-tests (propellant development, gelation, rheology, spraying, ignition, and combustion), a motor concept was pre-selected and the motor developed. The identified requirements were proven in December 2009 by two successful demonstration flights. The achieved know-how from basic research and technology $(\mathrm{R}+\mathrm{T})$ development has been consolidated in an application-oriented way on component level up to motor development. Within this scope, also, the goal of an effective control of the thrust by throttling the propellant mass flow rate (PMFR) while maintaining an optimum combustion chamber (CC) pressure could be achieved. This publication describes briefly several major advances in the development of the gel propulsion technology in Germany from rheology to combustor development to the thrust and pressure controller of a GRM.
\end{abstract}

(C) The Authors, published by EDP Sciences. This is an open access article distributed under the terms of the Creative Commons Attribution License 4.0 (http://creativecommons.org/licenses/by/4.0/). 


\section{NOMENCLATURE}

\section{Parameters}

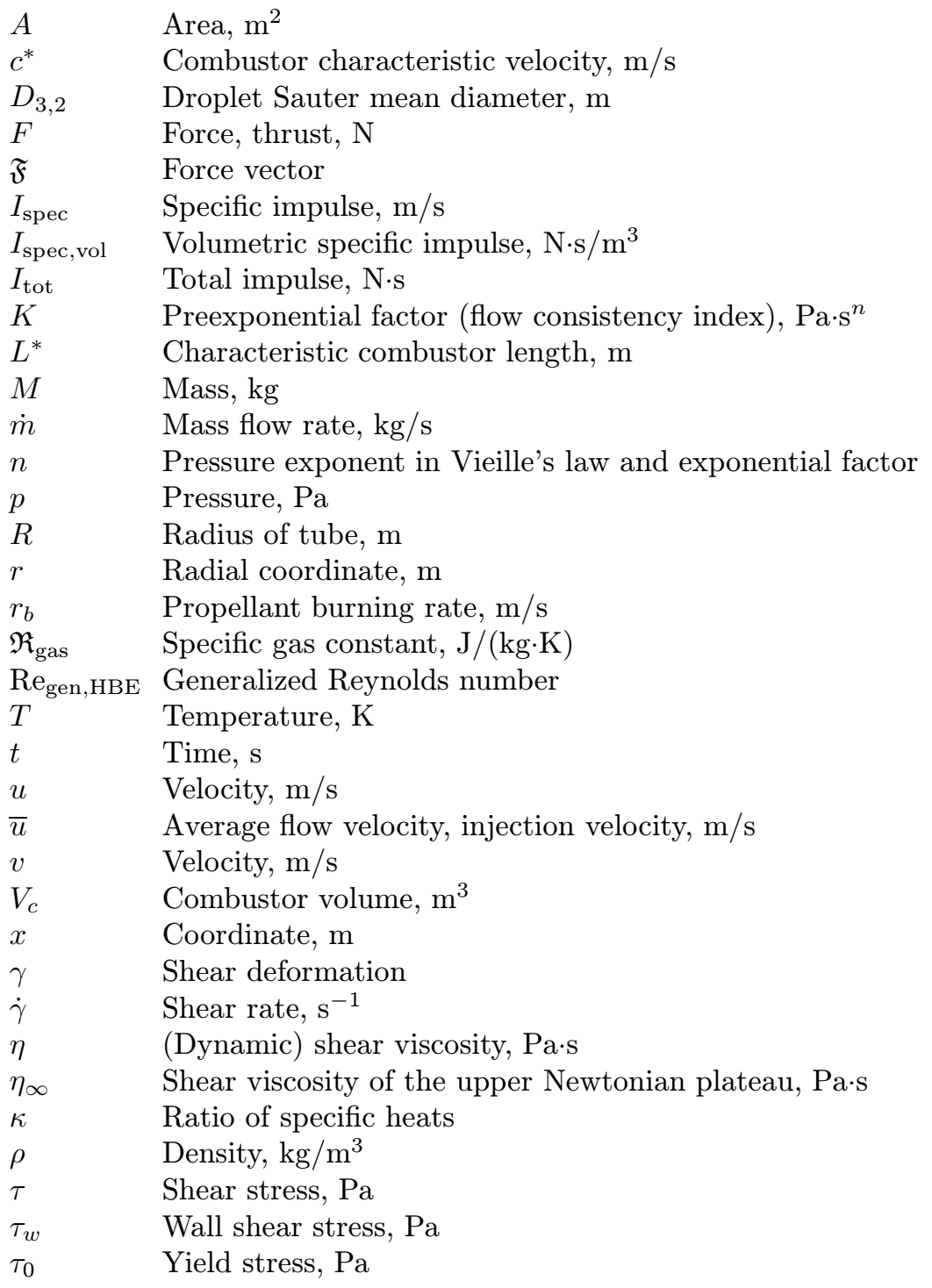

\section{Subscripts}

c Combustion

$e$ Condition at nozzle exit or at end of acceleration 


$\begin{array}{ll}\text { GRP } & \text { Gelled rocket propellant } \\ \max & \text { Maximum value } \\ N & \text { Nominal condition } \\ \text { op } & \text { Operation } \\ T & \text { Tank } \\ t & \text { Nozzle throat } \\ \text { tot } & \text { Total value } \\ \text { vac } & \text { Vacuum conditions } \\ 0 & \text { Reference condition } \\ \infty & \text { Ambient condition }\end{array}$

\section{Abbreviations}

ACS Attitude control system

BAAINBw Federal Office of Bundeswehr Equipment, Information Technology, and In-Service Support

BC Bayern-Chemie

BK-x Combustion chamber with diameter $x$

CC Combustion chamber

DACS Divert and attitude control system

DCS Divert control system

G-ACS Gel ACS

G-DACS Gel DACS

GG Gas generator

GGG Gelled propellant GG

GGPT German Gel Propulsion Technology (Program)

GRM Gelled propellant rocket motor

GRP Gelled rocket propellant

HBE Herschel-Bulkley Extended (equation)

HCCC Highly controllable CC

IM Insensitive munition

IRFNA Inhibited red fuming nitric acid

LP Liquid propellant

LRM Liquid propellant rocket motor

NTO $\quad \mathrm{N}_{2} \mathrm{O}_{4}$

PMFR Propellant mass flow rate

$\mathrm{R}+\mathrm{T} \quad$ Research and technology (development)

SGG Solid propellant GG

SP Solid propellant

SRM Solid propellant rocket motor

TD-B Technology demonstrator combustor process 


\section{INTRODUCTION TO GELLED PROPELLANT ROCKET MOTOR AND GAS GENERATOR TECHNOLOGY}

In the last two decades, a growing interest in gelled propellants or propellant combinations for rocket and ramjet propulsion applications can be observed worldwide. Gelled propellants have the potential to combine major positive properties of liquid and solid propulsion systems without combining major disadvantages. This means in detail that a GRM combines thrust variation on demand, i. e., an advantageous characteristic of liquid propellant rocket motors (LRM), with the easy handling and storage characteristics of solid propellant rocket motors (SRM). Also, for air-breathing ramjets, the use of gel propellants is advantageous because of better safety aspects in comparison to liquid propellants (LP).

This possibility to combine these above-mentioned properties is caused by the non-Newtonian rheological behavior of gels. Gels are solid at rest and are thus easy to handle and store, similar to solid propellants (SP). Under a sufficiently high applied shear stress, however, they can be liquefied whereas their viscosity decreases with increasing applied shear stress. Thus, the mass flow rate of gelled propellants can be varied, as it is typical for LRM and allows the design of engines with free thrust variation capability on demand. Moreover, energetic solid additives, like distinct metal particles, can be added to gelled propellants without sedimentation effects allowing a further increase of performance.

The origin for the development of a GRM was the demand to realize a rocket motor with variable thrust, easy handling and storage characteristics, and lower hazard potential than typical solid and liquid rocket motors $[1,2]$. The requirement of environmental friendliness on propellants and exhaust, commonly designated as "green propulsion," was also added [3]. For the GGPT Program [4], the absence of toxic and thus hazardous ingredients like hydrazine and its derivatives, $\mathrm{N}_{2} \mathrm{O}_{4}$ (nitrogen tetroxide, $\mathrm{NTO}$ ) and $\mathrm{HNO}_{3}$ (inhibited red fuming nitric acid, IRFNA) was an initial key requirement. The requirement of long-time storability of the propellants excluded ingredients that exhibit autocatalytic processes or are, otherwise, chemically unstable or are not storable under ambient temperature and pressure like $\mathrm{N}_{2} \mathrm{O}$ or cryogenic liquids.

A GRM or gelled propellant gas generator (GGG) shares with the LRM the separation of tank and CC and with SRM the essentially solid nature of the propellant as long as it rests in the tank. The essentially solid state of the propellant in the tank reduces the hazard potential significantly because in case of damage or an accident, the gelled propellant:

- does not spill;

- produces no large evaporation surface; 


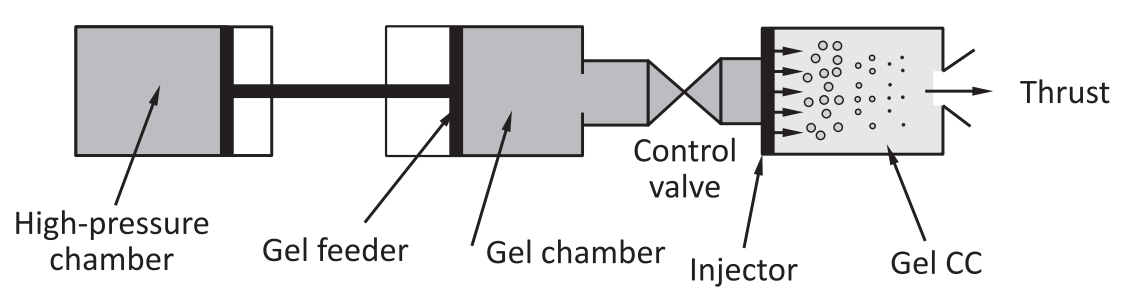

Figure 1 Principle of operation of a GRM

- has a much lower vapor pressure than the liquid; and

- does not soak into the ground .

Figure 1 shows a sketch of the principle of operation of a GRM. Like for LRM, thrust control is possible by control of the gelled PMFR. The key ingredients of an effective gelled rocket propellant (GRP) are a balanced blend of energetic fluids mixed with small amounts of efficient gelling agents. Additives can be used to modify the combustion behavior or other properties of the GRP. If tolerable, solid particles can be suspended in the gel to increase the $I_{\text {spec }}$ and/or the density of the GRP, because the nature of the GRP prevents sedimentation or buoyancy of incorporated particles even over long storage times. Gelled propellant rocket motors can be either bipropellant or monopropellant systems. Other properties that all functioning GRM share are:

- the GRP is fed to the CC by a pressure feeding system because a gel cannot be pumped, e.g., via turbopumps as in typical larger liquid rocket engines. For smaller liquid propulsion systems, however, pressure feeding systems were used. In most cases, this is driven by pressurization gases either produced by a gas generator (GG) or from a high-pressure gas reservoir. For a GRM, it is advantageous that a piston within a long cylindrical tank or a membrane within a short or spherical tank separate the GRP from the pressurizing gas;

- the GRP is injected into a CC in such a way that a spray of small droplets is formed. The very high shear rates produced during the injection process destroy the gel structure and the GRP behaves similar to an LP;

- the thrust level of the GRM can be either controlled by control of the GRP mass flow or by intermittent operation, and a GRM can be shut off on demand at any time; and

- the "solid" nature of GRP also prevents sloshing in the tank, if the tank is subjected to variable acceleration or vibration. 


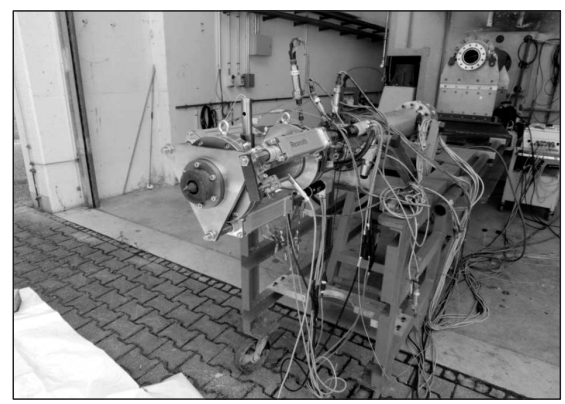

(a)

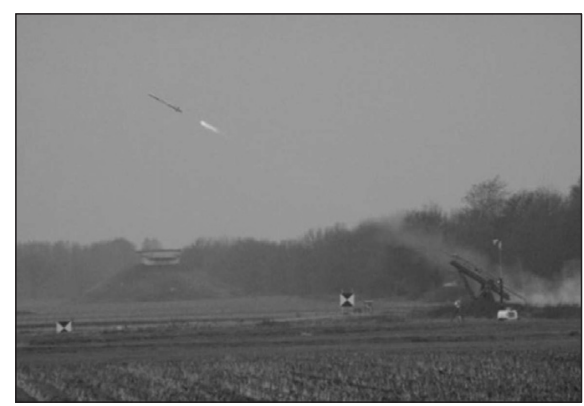

(b)

Figure 2 The highly variable CC on BC's static test facility $(a)$ and BC's GRM demonstrator missile just after launch $(b)$

The GGPT Program started in 2001 from a white sheet of paper, proposed by the DLR Institute of Space Propulsion, BC, and the Fraunhofer Institute of Chemical Technology to the German MoD's Federal Office of Bundeswehr Equipment, Information Technology and In-Service Support (BAAINBw) which funded the program continuously since 2002. Basic research work began at DLR in 1999. According to plan, in 2009, a monopropellant GRM with thrust modulation was demonstrated by two perfect flight demonstrations (Fig. 2). The following phases were dedicated to propellant development and to the development of a highly controllable CC (HCCC) shown in Fig. 2.

The scope of the present publication is to give a short overview on some major findings on $\mathrm{R}+\mathrm{T}$ development up to motor and component development. It condenses the main parts of the presentations of the Gelled Propellants Session at the EUCASS conference at Kraków, Poland, at the end of June 2015.

\section{GELLED PROPELLANTS}

Detailed $\mathrm{R}+\mathrm{T}$ development activities are necessary to optimize $\mathrm{CC}$ for gelled propellants. Due to the fact that these propellants are non-Newtonian shearthinning fluids, there is a strong influence of the rheological properties on flow, spray, and combustion behavior. Thus, the complex interplay of these different aspects has to be taken into account and has to be investigated in detail. This section gives a short insight in some major results.

\subsection{Rheology and Flow Behavior}

Gels can generally be described as shear-thinning non-Newtonian fluids with a distinct yield stress. Certain gels show additionally an elongational-thickening 

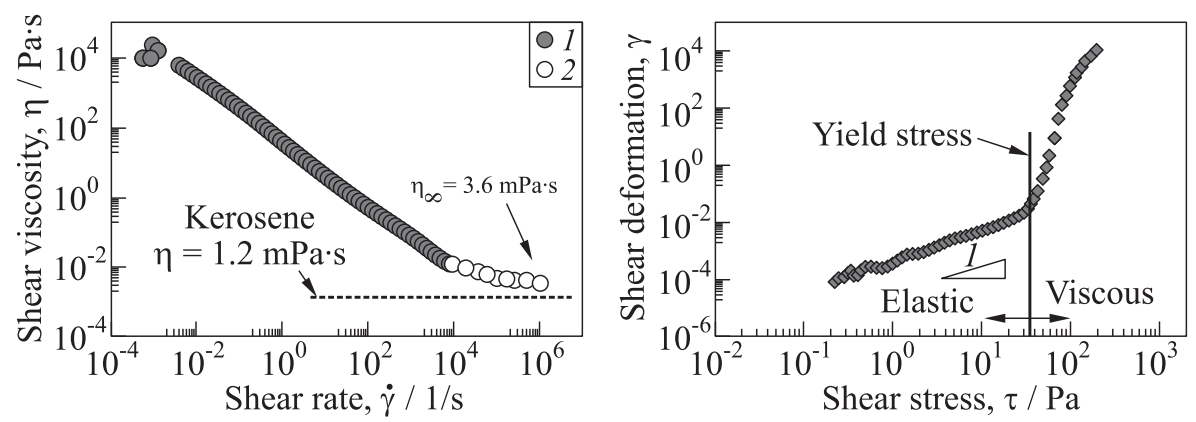

Figure 3 Dynamic shear viscosity $\eta$ vs. shear rate $\dot{\gamma}(a)$ (1 - rotational rheometry; and 2 - capillary rheometry) and determination of the yield stress $\tau_{0}(b)$ for a JetA-1/Thixatrol ST gel (GF3) [5]

behavior. Figure 3 presents the shear related rheological aspects of an example of a typical gel propellant (85\%(wt.) Jet A-1 (kerosene), 7.5\%(wt.) MIAK (methyl isoamyl ketone), and $7.5 \%$ (wt.) Thixatrol ST). Figure $3 a$ presents the dynamic shear viscosity $\eta$ in dependence of the shear rate $\dot{\gamma}$. It can be seen that the shear thinning behavior is significant: $\eta$ decreases in the order of almost 6 decades in the presented shear-rate range. At high shear-rates $\dot{\gamma}>10^{5} \mathrm{~s}^{-1}$, the shearthinning behavior diminishes due to the destruction of the gellant structure and leads to a constant viscosity value $\eta_{\infty}$, which is called upper Newtonian plateau and whose value is near the viscosity of the Newtonian basic fluid to be gelled (i. e., in this case, Jet A-1).

Furthermore, a typical gel shows a distinct yield stress $\tau_{0}$, which means that it behaves like an elastic solid when the shear stress applied to it is below the value $\tau_{0}$. When the stress applied to it exceeds the yield stress value, however, the gel starts to behave like a viscous fluid. Figure $3 b$ presents the dependency of the shear deformation $\gamma$ vs. the applied shear stress $\tau$. The deformation $\gamma$ increases up to the yield point in the log-log diagram linearly with a gradient of 1 , which is characteristic for an elastic region. When the yield stress increases above the yield stress, a stronger increase of the deformation is visible and the gel starts to flow.

The three aspects of the shear relevant rheological behavior of a gel, i.e., shear-thinning, upper Newtonian plateau, and yield stress, can be described by a constitutive equation, which is called Herschel-Bulkley Extended (HBE) equation $[6]$ :

$$
\eta_{\mathrm{HBE}}=\frac{\tau_{0}}{\dot{\gamma}}+K \dot{\gamma}^{n-1}+\eta_{\infty}
$$

This equation describes the dependence of the shear viscosity on the shear rate with a satisfying accuracy in the whole propulsion relevant shear rate range. 
This range covers eight decades within $10^{-2}<\dot{\gamma}<10^{6} \mathrm{~s}^{-1}$ from storage up to the flow through suitable injectors.

Several gels show additionally an extensional-thickening rheological behavior. This means that a fluid (element) shows an appreciable resistance if it is stretched out or squeezed down and this resistance increases with increasing strain rate. The value of the extensional viscosity is often taken as an indicator of the intensity of nonlinear viscoelastic effects. This effect is strongly related to the nature of the gelling agent. Fluids, which are gelled with cross-linked polymers or silica particles, show generally almost no elastic effects under large deformations, due to the fact that the three-dimensional structure formed by the gelling agent breaks up under large deformation. Linear polymers, however, strongly influence the nonlinear elasticity, because the linear molecules are stretched in the gel under large deformation and generate normal forces inside the fluid. The occurrence of extensional viscosity influences the spray behavior of propellants as it will be shown in the subsequent subsection. Detailed information on the elongational-thickening behavior of gels and its influence on the spray behavior is given in [7-9].

The flow behavior of non-Newtonian fluids shows several differences to Newtonian fluids. Newtonian fluids have a parabolic velocity profile for flows through tubes of constant diameter under laminar, fully developed, incompressible, and steady-state conditions. Shear-thinning (power-law type) fluids, however, show a "broader" velocity profile with lower dimensionless centerline velocities (local velocity $u(r)$ divided by average flow velocity $\bar{u}$ ) and steeper gradients near the tube wall. In the case of fluids with a distinct yield stress, a flow region with a constant velocity occurs around the tube centerline, which is caused by shear stresses lower than the yield stress of the fluid as can be seen for four typical gel propellants with HBE fluid in Fig. 4. The size of this plug flow region depends
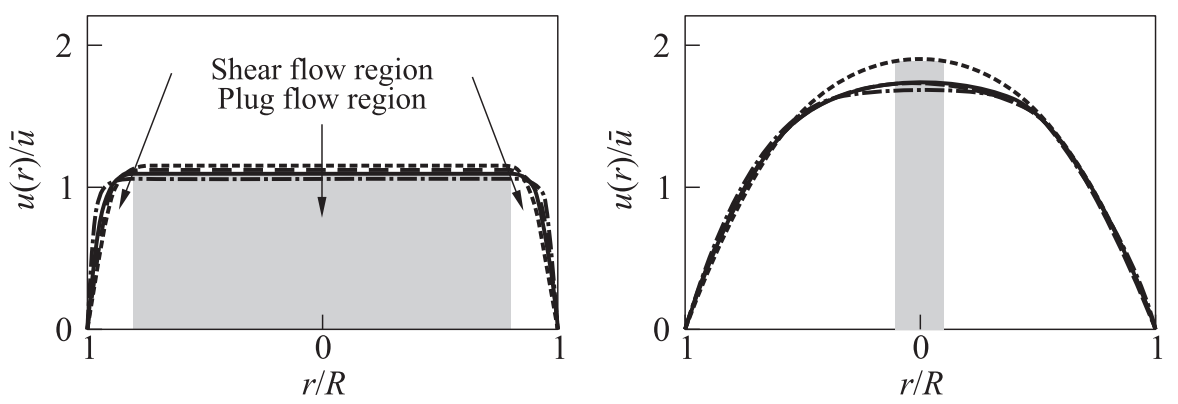

Figure 4 Dimensionless laminar velocity profiles in tubes for different gel test propellants at two different $\tau_{0} / \tau_{w}$ values: $0.8(a)$ and $0.1(b)$. Different lines represent the velocity profiles of four different gels with different viscosity curves [10] 


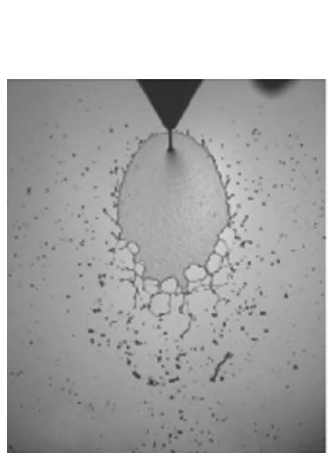

(a)

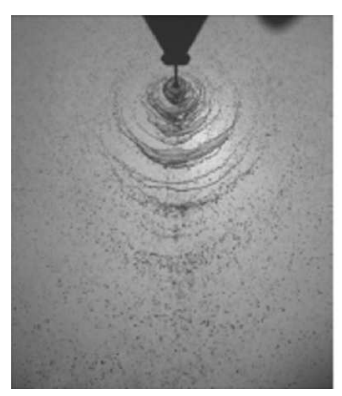

(c)

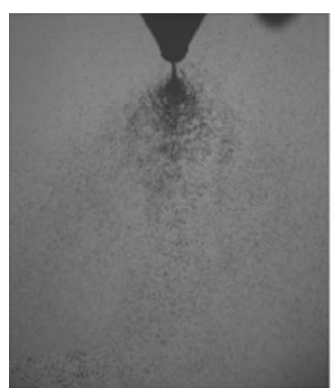

(e)

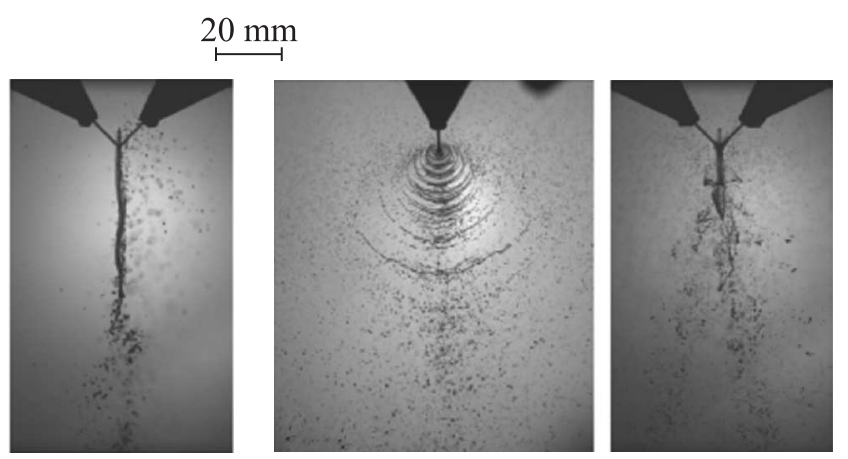

(b)
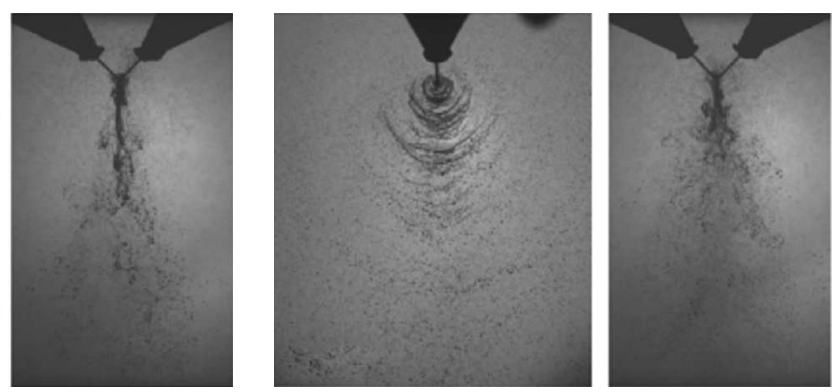

$(d)$
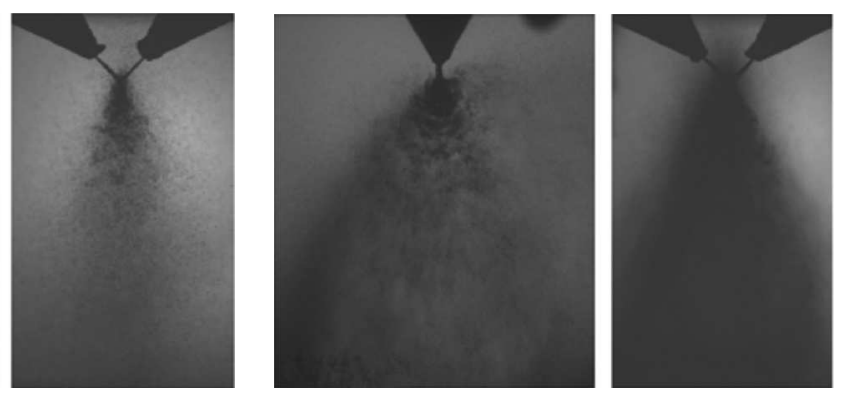

$(f)$

Figure 5 Breakup process with droplet formation of the kerosene/Thixatrol gel (GF3) in dependence of injection velocity and generalized HBE Reynolds number [5]: (a) $\bar{u}=5 \mathrm{~m} / \mathrm{s}, \operatorname{Re}_{\text {gen HBE }}=470$ (rimless); $(b) \bar{u}=8 \mathrm{~m} / \mathrm{s}, R_{\text {gen HBE }}=800$ (ligament structures); $(c) \bar{u}=12 \mathrm{~m} / \mathrm{s}, \operatorname{Re}_{\text {gen HBE }}=1335$ (ligament structures); $(d) \bar{u}=16 \mathrm{~m} / \mathrm{s}$, $R_{\text {gen HBE }}=1705$ (ligament structures); $(e) \bar{u}=31 \mathrm{~m} / \mathrm{s}, \operatorname{Re}_{\text {gen HBE }}=3805$ (fully developed pattern); and $(f) \bar{u}=73 \mathrm{~m} / \mathrm{s}, \operatorname{Re}_{\text {gen } \mathrm{HBE}}=10710$ (fully developed pattern) 
on the ratio of the yield stress to the stress at the wall $\tau_{0} / \tau_{w}$ and is thus more pronounced at lower average flow velocities $\bar{u}$. For lower stress ratios $\tau_{0} / \tau_{w}$ and thus higher $\bar{u}$, not only the plug flow region gets smaller. Also, the velocity profiles are approaching to the Newtonian parabolic profile, which is caused by reaching the constant and thus limiting lowest viscosity value $\eta_{\infty}$ at the upper Newtonian plateau.

\subsection{Propellant Injection and Spray Behavior}

In suitable injectors, sufficiently high shear rates must be produced to decrease the shear viscosity to the necessary low values which are needed to liquefy the gel propellant. Due to the significantly longer relaxation time of a sheared gel in comparison to characteristic times of the spray processes, gels can be atomized to necessary small droplet sizes which are needed in combustors. The conducted spray experiments could demonstrate that impinging jet injectors are suitable for this task. Figure 5 shows pairs of shadowgraph images of the spray behavior of a kerosene/Thixatrol gel as an example of a droplet forming gel. The experimental setup contains a modular like-on-like doublet impinging jet injector, where various parameters can be varied. Further information of the setup is given, for example, in $[7,8]$. The pairs of images were obtained from perpendicular directions, showing a perpendicular view and a view from the side on the fluid sheet which is formed at the impingement point of the two fluid jets. This sheet decays downstream to smaller ligaments and droplets. It is obvious that with increasing fluid injection velocities $\bar{u}$ (and thus increasing generalized HBE Reynolds numbers $\mathrm{Re}_{\text {gen,HBE }}$ [5]), smaller droplets are produced.

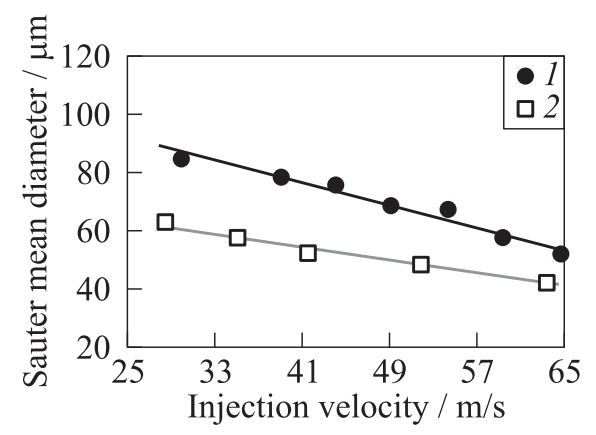

Figure 6 Atomization of gels containing $30 \%$ micro-Al (MEP 027) (1) and 30\% nano$\mathrm{Al}$ (Alex) (2) [11] droplet diameters (expressed here as Sauter mean diameter $D_{3,2}$ ) are smaller (Fig. 6). Unfortunately, the combustion experiments have not been very suc- 


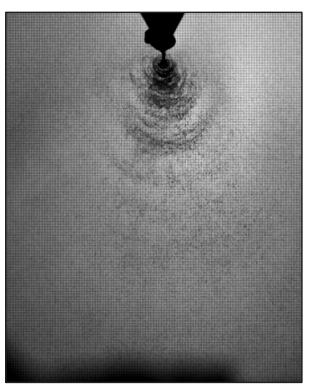

(a)

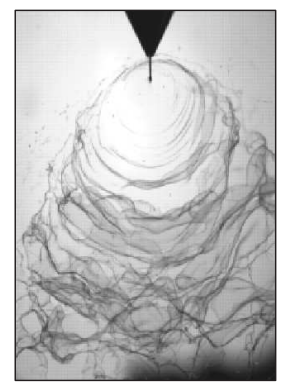

(b)

Figure 7 Comparison of droplets and threads formation: $(a)$ ethanol $+10 \%$ COK 84, $\bar{u}=45.5 \mathrm{~m} / \mathrm{s} ;$ and $(b)$ water $+3.1 \%$ Methocel J12MS, $\bar{u}=46.8 \mathrm{~m} / \mathrm{s}[12]$

cessful. The formation of large aggregates of aluminum was observed, which left the CC with limited oxidation. The formation of such aggregates could explain why the substitution of micro-Al with nano-Al did not lead to the expected increase in combustion efficiency [11].

As mentioned in subsection 2.1, several gels show a distinct elongationalthickening (rheological) behavior. Figure 7 shows the difference in the spray behavior between a gel with a very low (Fig. $7 a$ ) and a gel with a high elongational viscosity (Fig. $7 b$ ). It is obvious that for the gel with the high elongational viscosity, threads are formed instead of small droplets. These structures have a significantly lower specific surface contact area with the surrounding atmosphere when compared to droplets and thus could lead to a decrease in combustion efficiency in the limited length of a combustor and the accumulation of unburned material at the wall of the CC. Detailed information on the origin of thread formation is given, for example, in $[12,13]$.

\subsection{Gel Combustion Process}

The combustion process of gel propellants in mono- and bipropellants rocket model combustors as well as under ramjet relevant conditions has been studied extensively at the M11 test complex at DLR at Lampoldshausen test site. This subsection can only show some examples of the extensive $\mathrm{R}+\mathrm{T}$ development activities.

\subsubsection{Combustion of gelled ramjet propellants}

Ramjet engines are, beside rocket engines, another important application area. At DLR Lampoldshausen, mainly, basic experiments were conducted for a better 
understanding of spray and combustion processes. Based on this, the obtained results are interesting for lab scale ramjet combustor experiments, which are nearer to real combustor geometries (see, e.g., $[14,15]$ ).

Basic combustion experiments of metallized and nonmetallized gel propellant sprays with a hot (vitiated) air flow under ramjet relevant conditions concerning combustor pressure and air inlet temperature were conducted in a large windowed chamber. The results were presented in several publications (see, e.g., [13, 16, 17]).

Using this experimental setup, a detailed analysis was conducted on the combustion of gelled propellants containing micro- and nanosized aluminum particles. The results were published recently in [11]. The use of nano-Al does not have any positive influence on the combustion efficiency as mentioned above. The combustion products of distinct experiments were collected using rapid insertion probes. The formation of large aggregates was observed. The formation of aggregates may explain why the use of nano-Al does not lead to an increase in combustion efficiency under these experimental conditions. The higher reactivity of nano-Al is due to its large specific surface area. The specific surface area of large aggregates, however, is much lower, which effectively reduces the reactivity of the nano- $\mathrm{Al}$ particles.

\subsubsection{Gelled rocket propellants - experimental setup}

The facility realized to investigate the combustion of GRP is called Gel Technology Demonstrator Combustor Process TD-B. The test bench consists of modular model combustors, a thrust balance, an ignition system, and a propellant feeding system. The test runs are conducted though a remote controlled system and supervised from a separated control room. The gel propellants feeding system is in its main features similar to the cartridge system used for the investigations on spray behavior. The propellant gels are stored in two large steel cartridges with movable pistons inside. By moving the pistons with a hydraulic unit, the gels are pushed into the feeding lines to the injector head. This system allows remote controlled feeding of gels with different rheological properties with preselected volumetric flow rates. These preselected flow rates can be varied during a test run and are independent from the pressure drop inside the injection system, etc. Gel flow rates up to $500 \mathrm{~cm}^{3} / \mathrm{s}$ can be fed if both cartridges are used in parallel.

The modular design allows test activities with various types of injector heads and injection geometries. Test runs, e.g., with different numbers and designs of doublet impinging jet injector elements as well as with single triplet elements were successfully conducted.

On this gel propulsion test bench, the first thrust variation of a gel model combustor in Germany could be demonstrated in 2005 (see, e.g., [14]). 


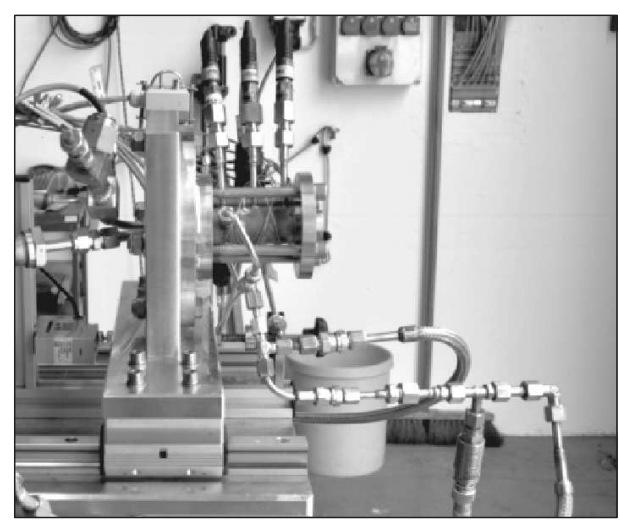

(a)

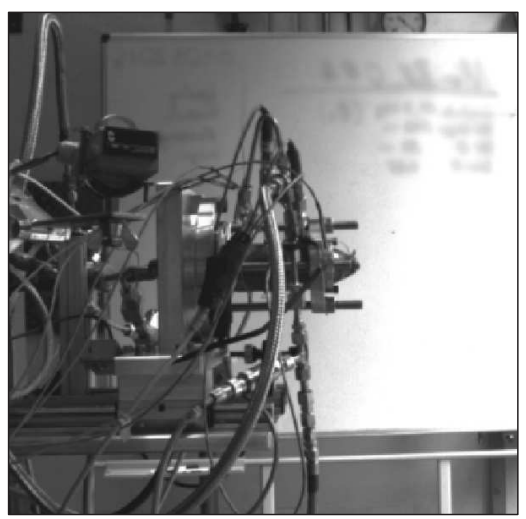

(b)

Figure 8 Test bench with the small model combustor BK-20.6 in the version with 80millimeter length $(a)$ and BK-50 with 140-millimeter chamber length $(b)$

Various gel monopropellants and gelled propellants and oxidizers with different gellants and additives in different concentrations were tested at this facility since it came into service.

In the first generation of gels for propulsion testing, mainly Aerosil particles (fumed silica) were used as gellants. Due to their inertness and the danger of the formation of residues inside the combustor, gels with other gellants were developed with support of Fraunhofer-ICT and tested. Using these new gels with nearly no residual aggregation and the positive effect of used ingredients on the combustion efficiencies, it was possible to conduct tests with smaller CC.

Currently, two modular combustor setups are used, one with an internal combustor diameter of $50 \mathrm{~mm}$ (BK-50) and one with a diameter of $20.6 \mathrm{~mm}$ (BK-20.6).

Both combustor setups (Fig. 8) can be used with capacitive cooled steel CC of different lengths. The combustor lengths can be varied in steps up to $400 \mathrm{~mm}$. Figure $8 a$ shows the smaller model combustor BK-20.6 (inner diameter $20.6 \mathrm{~mm}$ ) with a short chamber tube length of $80 \mathrm{~mm}$.

For a smooth ignition of the gel propellants, an $\mathrm{H}_{2} / \mathrm{O}_{2}$ torch igniter is used. At the start of a test run, the combustion is supported for a short time by surplus oxygen feed into the CC to speed up the transient start-up phase. Igniter and oxygen are then both turned off after start-up. Depending on the operation conditions, the heat load of the $\mathrm{CC}$ wall ranged approximately from 1 to $3 \mathrm{MW} / \mathrm{m}^{2}$. Therefore, the heat capacity of the CC allowed test durations of 6 to $9 \mathrm{~s}$. 


\subsubsection{Combustion of gelled rocket propellants - results and discussion}

The main goal of the test campaign conducted with BK-20.6 and BK-50 is the determination of the conditions to obtain a more efficient combustion. The quality of the combustion was assessed by calculating the characteristic velocity $c_{\exp }^{*}$ for each test. It is determined from the effective chamber stagnation pressure $\left(p_{c}\right)$, the throat area $\left(A_{t}\right)$, and the throat mass flowrate $(\dot{m})$ :

$$
c_{\exp }^{*}=\frac{p_{c} A_{t}}{\dot{m}} .
$$

The JANNAF (Joint Army-Navy-NASA-Air Force) methodology was used to obtain the value of characteristic velocity from the test runs. The measured static pressure is corrected to the effective chamber stagnation pressure, since no correction for boundary layer effects and heat losses are applied, the presented $c^{*}$ values represent $c_{\text {test }}^{*}$ values following the JANNAF nomenclature. Furthermore, ANSYS Mechanical 15.0 simulation was used to estimate the pressure and thermal induced deformation of the throat area. First step for this simulation was a transient-thermal-stress analysis with axial heat flux as load profiles for multiple time steps. This provides the spatial temperature profile that together with the pressure is the input for a subsequent static mechanical analysis and gives the total stress deformation of the throat area during the test run time. To determine the mass flow rate, the measured volumetric flow rate has to be converted with the density of the gel propellant.

Figure 9 presents results from test runs with the two CC. In the diagrams, the values of the combustion characteristic velocity determined during the tests, $c_{\exp }^{*}$,
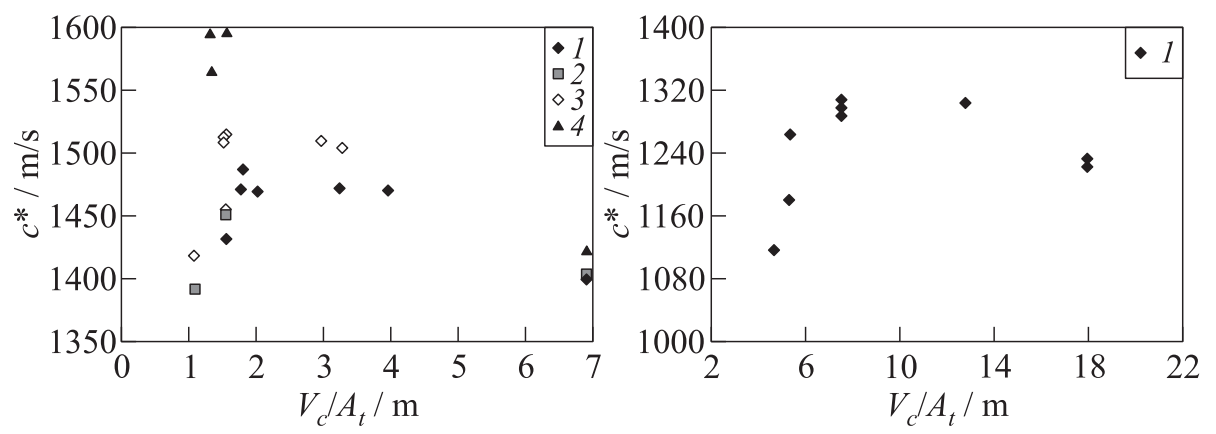

Figure 9 Combustion characteristic velocity $c^{*}$ vs. the characteristic chamber length $L^{*}=V_{c} / A_{t}$ : (a) combustor diameter $20.6 \mathrm{~mm}$ (BK-20.6); (b) combustor diameter $50 \mathrm{~mm}(\mathrm{BK}-50) ; 1-p_{c}=50$ bar; $2-60 ; 3-70$; and $4-p_{c}=80$ bar 
are presented in dependence of the characteristic chamber length, $L^{*}$, defined as the ratio of CC volume to nozzle throat area: $L^{*}=V_{c} / A_{t}$.

From the diagrams in Fig. 9, the optimal characteristic combustor length $L_{\mathrm{opt}}^{*}$ can be determined as the $L^{*}$ corresponding to the maximal $c_{\exp }^{*}$. The value of $L_{\mathrm{opt}}^{*}$ is important for the design of CC. If the CC is too small, i. e., $L^{*}<L_{\mathrm{opt}}^{*}$, the stay time of the reacting products in the $\mathrm{CC}$ is too short in order to allow a complete combustion. On the other hand, if the chamber is too large, i. e., $L^{*}$ $>L_{\text {opt }}^{*}$, the combustion will be complete in the chamber, but the hot reaction products will lose energy through heat transfer to the CC walls before the expansion in the nozzle. Both situations should be avoided as they lead to lower combustion efficiency compared to the optimal case.

In the presented campaign, the length of the model combustor BK-20.6 was stepwise reduced from 400 to $80 \mathrm{~mm}$. Two different nozzles were tested, with throat diameters $d_{t}$ of 5 and $6 \mathrm{~mm}$. Consequently, the $L^{*}$ varied from 7 to $1 \mathrm{~m}$. The mass flow rate was varied in order to obtain CC pressures between 50 and 80 bar. A chamber pressure of 50 bar was obtained with $0.088 \mathrm{~kg} / \mathrm{s}$ mass flow rate and 6 -millimeter nozzle diameter. The value of the optimal characteristic chamber length, $L_{\mathrm{opt}}^{*}$, for the lower pressure level (around 50 bar) was determined as approximately $1.8 \mathrm{~m}$ with setup described. For the higher pressure level (around 70 bar), higher combustor characteristic velocities $c_{\exp }^{*}$ were observed for smaller $L^{*}$, leading to a smaller $L_{\text {opt }}^{*}$ value of approximately $1.5 \mathrm{~m}$. Therefore, $L_{\mathrm{opt}}^{*}$ is dependent of the CC pressure.

From the diagrams in Fig. 9, the optimal characteristic combustor length $L_{\mathrm{opt}}^{*}$ can be determined as the $L^{*}=V_{c} / A_{t}$ at maximum $c^{*}$, i. e., the necessary smallest characteristic combustor length with an efficient combustor process. This value is important for the realization of compact and efficient CC. For the lower pressure level around $50 \mathrm{bar}$, the $L_{\mathrm{opt}}^{*}$ of this hardware and the used gelled propellant was determined as approximately $1.8 \mathrm{~m}$.

For the higher pressure level around 70 bar, higher combustor characteristic velocities $c^{*}$ were observed for smaller $V_{c} / A_{t}$. Thus, a smaller $L_{\mathrm{opt}}^{*}$ could be determined at approximately $1.5 \mathrm{~m}$. So, a pressure influence on $L_{\mathrm{opt}}^{*}$ and $c^{*}$ is visible. In tests with the larger $\mathrm{CC}$ BK-50, however, smaller combustion characteristic velocities $c^{*}$ were found at higher $L^{*}=V_{c} / A_{t}$. For the BK-50, $L_{\mathrm{opt}}^{*}$ is estimated to be $7.5 \mathrm{~m}$.

The difference in the combustion characteristic velocity $c^{*}$ indicates a more compact and efficient combustor process within the smaller model combustor BK-20.6. The longer residence times in the larger model combustor may be a hint to different combustor processes. It can be assumed that in the smaller chamber, a spatial more concentrated or compact combustion region exists which enhances the energy transfer between the areas with combustion and the areas with the spray, leading to speed up in droplet heat-up and atomization. Which influence secondary atomization effects due to spray/chamber wall interactions have is unknown and detailed further investigations are necessary. 


\section{GELLED PROPELLANT ROCKET MOTORS AND GAS GENERATORS}

This section describes the development of the GRM/GGG at BC. It begins with an introduction to the general principle of operation of a GRM. It is followed by a description of the GRPs environmental and performance guidelines and hazard characteristics. A brief overview of the control algorithms developed for the GRM follows. The section ends with a summary of 5 representative GRM trials conducted at $\mathrm{BC}$.

\subsection{Principle of Operation}

From the tank, the GRP, where it behaves at rest like a solid, has to be fed into the CC by pressure. The feeding pressure can be generated by a high-pressure gas tank or a solid propellant GG (SGG) $[4,18]$ dependent on what fits best to the specific requirements of a concept. Depending on the tank shape, a piston or a membrane separates the feeding gas and the GRP. The propellant mass flow is controlled by a valve. Upon injection into the CC, the structure of the gel is destroyed and the gelled propellant is sprayed like a liquid. An igniter starts the combustion. Solid propellant pyrotechnic igniters as well as gas igniters have been demonstrated.

A nozzle of variable area makes it possible to decouple the pressure in the $\mathrm{CC}$ from the PMFR. With the combination of mass flow valve and control nozzle an exact control of the thrust (through the mass flow rate) and of the optimal pressure at the $\mathrm{CC}$ is possible.

\subsection{Green Gelled Propellant Rocket Motor Characteristics and Performance}

The propellant development guidelines of the GGPT Program are:

- a GRP that is storable for long durations, at least 10 years;

- to use ingredients not particularly toxic, carcinogen, acid, or in other respects harmful for people or the environment, because the hazard potential of these materials would disqualify them for use in military applications. This disqualifies ingredients like hydrazine or its derivatives and oxidizers like dinitrogen tetroxide or nitric acid; and

- to develop GRP formulations that cover as widely as possible also the military relevant operational temperature range from -40 up to $+71{ }^{\circ} \mathrm{C}$. This also excluded aqueous solutions of many oxidizer salts. 
The first result of the development activities was a monopropellant throttleable GRM system burning GRP-001 that was demonstrated by two successful flight tests in December 2009 [18]. Since then, the goal of the activities has been to improve the functional and performance parameters of the motor. Key properties of the monopropellant system are:

- stable start and combustion;

- throttleability;

- wide turndown range;

- a family of monopropellants with different gelling agents, liquid and solid ingredients, and additives;

- good scalability of the GRM over the nominal thrust range of 300 to $6000 \mathrm{~N}$ at atmospheric pressure;

- environmental friendliness of propellant and exhaust gas;

- little primary and secondary smoke if no solid additives are used;

- good handling, transport, and storage properties;

- long storage time. An environmental test program similar to that for an SRM, covering 5 years of lifetime was carried out for a GRM with GRP001 (Table 1) and after this program, the GRM showed no degradation at a static firing test;

- high degree of insensitivity. Tests with GRP-001 carried out at the Federal Institute for Materials Research and Testing (BAM) yielded the rating "no explosive." Insensitive munitions (IM) tests carried out at WTD 91 showed mild burning under propellant fire, slow heating and bullet attack, and no reaction under fragment attack. A more detailed assessment of the hazard potential of different propellant systems is given in [3];

- a wide operational temperature range;

- ignition by SP igniters and an external gas lancet has been demonstrated; and

- monoblock SGG designs for tank pressurization that allow to cover within a given time frame various thrust profiles and a method to predict the tank pressure histories dependent on thrust course and GG design which can be used to optimize the ballistic behavior of the GG. 
Table 1 Key parameters of the GRP family $\left(p_{c} / p_{\infty}=70: 1\right)$

\begin{tabular}{cccc}
\hline Gel & $\begin{array}{c}I_{\text {spec }}, \\
\mathrm{N} \cdot \mathrm{s} / \mathrm{kg}\end{array}$ & $\begin{array}{c}T_{c}, \\
\mathrm{~K}\end{array}$ & $\begin{array}{c}\rho, \\
\mathrm{g} / \mathrm{cm}^{3}\end{array}$ \\
\hline 001 & 2194 & 2144 & 1.13 \\
002 & 2512 & 2795 & 1.31 \\
003 & 2236 & 2089 & 1.18 \\
004 & 2586 & 2910 & 1.28 \\
005 & 2080 & 1883 & 1.17 \\
006 & 2182 & 1981 & 1.16 \\
007 & 1900 & 1396 & 1.11 \\
008 & 1878 & 1375 & 1.09 \\
009 & 2143 & 1904 & 1.19 \\
013 & 2290 & 2536 & 1.41 \\
014 & 2178 & 1857 & 1,14 \\
015 & 2467 & 2770 & 1.38 \\
016 & 2465 & 2809 & 1.38 \\
017 & 2423 & 2650 & 1.38 \\
018 & 2135 & 2574 & 1.42 \\
019 & 1990 & 1438 & 1,11 \\
026 & 2622 & 3150 & 1.49 \\
039 & 2629 & 3180 & 1.55 \\
\hline
\end{tabular}

A penalty to be paid for the high degree of insensitivity is that the GRM needs a comparatively powerful ignition system which complicates the design of a GRM with repeatable ignition. Hypergolic systems and nonhypergolic bipropellant systems are a topic of actual basic research activities, but not yet sufficiently mature to build a rocket motor.

Table 1 gives an overview on theoretical specific impulse $I_{\text {spec }}$, density $\rho$, and theoretical combustion temperature $T_{c}$ of the different propellants of BC's GRP family. The theoretical performance of the propellants has been validated by a campaign of performance test runs. Looking for ballistic performance, the maximum $I_{\text {spec }}$ of GRP-002, GRP-004, and GRP-013 (for example) is comparable to that of classic moderately aluminized propellants with HTPB (hydroxylterminated polybutadiene) as a binder and ammonium perchlorate as an oxidizer. Other propellants like GRP-007, GRP-008, GRP-010, or GRP-019 have a low combustion temperature and are suited for the use in GG that pressurize volumina, e.g., tanks, produce the driving gas for mechanical assemblies or for divert and attitude control systems (DACS). By blending of different ingredients, the combustion temperature of the gelled propellant can be adapted to the thermal sustainability of the mechanical structures, e.g., valves, or other gas flow control, or energy conversion systems that are subjected to the combustion products. Notice that the density of the GRP tends to be higher than that of LP which are currently in use.

\subsection{Hazard Characteristics of Gelled Propellant Rocket Motor}

Compared to LRM, a GRM in general has by nature a lower hazard potential because in case of an accident or impact, the propellants spill not out and have a much lower vapor pressure. This avoids violent combustion and reduces significantly the soaking of unburnt propellant into soil or sewers and the consequential efforts needed to clean up the mess. Compared to SRM, the propellants are not explosives, which reduce the effects of blast waves and fragments. Nevertheless, 
in military applications up till now, SRM are preferred because their hazard potential is well defined. Beyond blast waves and projection of fragments, the environmental impact is very limited in severity and persistence.

For military operations, only propellants that are storable for long times at ambient temperature and a wide range below and above can be used. Because the established storable LP like $\mathrm{N}_{2} \mathrm{H}_{4}, \mathrm{MMH}$ (monomethylhydrazine), $\mathrm{N}_{2} \mathrm{O}_{4}$, and $\mathrm{HNO}_{3}$ have a high hazard potential in case of accidents, aggressions, and malfunctions [19], LRM have been sorted out of military arsenals. In civil applications, some of these propellants come under increasing pressure by REACh (Registration, Evaluation, and Autorization of Chemicals) regulations. $\mathrm{N}_{2} \mathrm{H}_{4}$ has been put on the list of substances of very high concern (SVHC) due to its toxicity and its suspected of causing cancer. $\mathrm{H}_{2} \mathrm{O}_{2}$ and $\mathrm{N}_{2} \mathrm{O}$ are environmentally friendlier, but may cause violent chemical reactions and $\mathrm{H}_{2} \mathrm{O}_{2}$ shows intrinsic decomposition with gas production over long storage times. Solutions of ammonium dinitramide (ADN) or hydroxylammonium nitrate (HAN) in liquids like LMP-103S and AF-M315E are environmentally friendly, but existing small thrusters need preheated catalysts [3]. It is obvious that these energetic ionic liquids are suited actually only for small thrusters up to about $500 \mathrm{~N}$. Another deficit is the rapidly decreasing solubility of the salts with decreasing temperature. Further information about ionic LP is given in [17].

The strict requirements of future civil and military customers lead to a GRM technology that is as "green" as storable propellants can be. Despite of the use of monopropellants, here presented GRM has a very low hazard potential and a high degree of insensitivity. Tests with GRP 001 yielded IM reaction levels of VI for fragment impact and V for bullet impact, slow heating, and fuel fire [4]. The propellants and the GRM have very good manufacturing, handling, transport, and storage properties and pose low risk to personnel and environment by criteria described in [3]. By nature, a monopropellant GRM is inherently safe against unintended operation because three independent inputs: pressurized tank, open fuel flow control valve, and ignition are necessary to set a monopropellant GRM into operation.

\subsection{Gelled Propellant Rocket Motor Control Algorithms}

Assuming perfect gas law theory, the throat area can be computed as a function of mass flow and CC:

$$
\left.\begin{array}{rl}
\dot{m} & =\frac{p}{\mathfrak{R} T} \sqrt{\kappa \mathfrak{R} T} A^{*} ; \\
T & =T_{t}\left(1+\frac{\kappa-1}{2}\right)^{-1} ; \\
p & =p_{t}\left(1+\frac{\kappa-1}{2}\right)^{\kappa /(\kappa-1)}
\end{array}\right\}
$$


where $T_{t}$ and $p_{t}$ are the temperature and pressure at the nozzle throat, respectively. The parameters for the hot gases were computed from the GordonMcBride NASA code. The gel mass flow or PMFR can then be computed from the movement of the piston.

The mass flow rate depends on the valve cross section area, feeding pressure in the GG, and pressure in the $\mathrm{CC}$ and it is given by the mass flow through a control valve equation:

$$
\dot{m}=K_{v} \sqrt{\left(p_{\text {luft }}-p_{\text {cc }}\right)} \rho
$$

where $K_{v}$ is the value (or mass flow coefficient) that has been determined from a series of flow checks for our specific system.

The control of the propulsion subsystem during flight is realized as a cascaded control loop for the missile thrust and CC pressure. The motor control receives a thrust demand together with the estimated current thrust and tries to match the thrust demand by varying the mass flow control valve position while maintaining optimal CC pressure by adjusting the nozzle position. For the purpose of analyzing the motor and controller behavior during the sustain phase, only the cascaded thrust, pressure, and valve control loops are considered.

The main controller components can be divided into the following categories:

- monitoring functions. The monitoring functions logic allows for a comprehensive knowledge of the motor variables state. The output of the block includes, but is not limited to, estimations of the remaining mass propellant, PMFR, estimated thrust, soak temperature, and firing detection;

- thrust control loop. The outer control loop is the thrust controller, which receives the command thrust as well as relevant motor and environmental parameters. The thrust loop controller is a gain scheduled PI (proportional integral) with a feed forward loop. The flight parameters external to the motor which are inputs of the FCL (fuzzy control language) logic are the ambient pressure, altitude, and soak temperature. The main motor parameters are the estimated thrust and the CC pressure. The feed forward term is based on a lookup table that estimates the necessary valve opening to achieve the commanded thrust, based on the system parameters and on (1). An additional logic actively tracks the system and moderates thrust commands that might cause instability;

- pressure control loop. The pressure controller is a gain scheduled PID (PI derivative) controller combined with a feed forward term. Within this controller, the nozzle valve area to achieve the optimal CC pressure is computed. The controller measures the current pressure within the CC through pressure sensors. The feed forward term is based in Fig. 10; and 


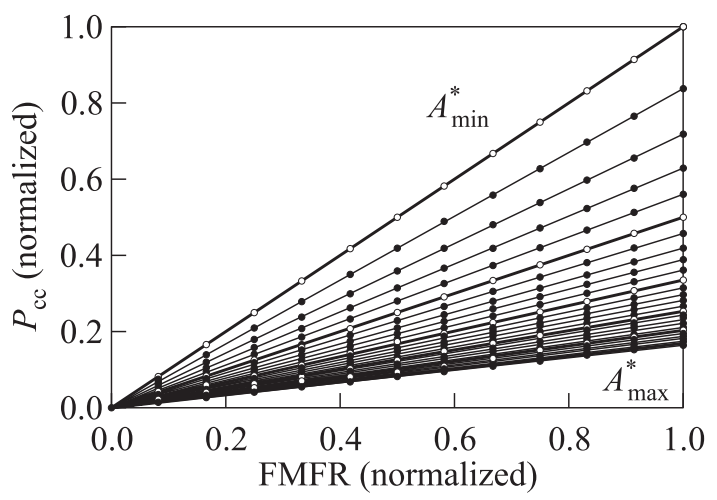

Figure 10 Combustion chamber pressure as a function of the fuel mass flow rate (FMFR) and throat area for a specific GRP

- injection head control loop. The number of active injectors is optimized in order to guarantee enough mass flow through each active injector into the $\mathrm{CC}$ and, at the same time, to maximize the cooling by heat dispersion of the injection head.

The controller is activated according to a four-stage logic:

(1) launch/ignition: the pressure demand from FCL is ignored; the valve and nozzle are fully closed;

(2) open loop control: only the feed-forward path is active during a predetermined time after ignition;

(3) transition from Open to Close loop control: the feedback loop is closed, but with sliding $\mathrm{P}+\mathrm{I}$ gains: the gains increase linearly from an initial value of zero up to their nominal value; and

(4) fully functional closed loop control.

\subsection{Gelled Propellant Rocket Motor Control Experiments}

In order to demonstrate the performance and controllability of the motor, 5 representative trials are shown. These are summarized in Table 2. They consist of one trial with a fully opened nozzle and a constant CC pressure of 40 bar and a second trial performed with variable pressure in the CC. The particular GRP that has been used has a stable combustion for pressures of around 30 bar and above. 
Table 2 The GRM trials

\begin{tabular}{ccl}
\hline $\begin{array}{c}\text { Test } \\
\text { run } \\
\text { name }\end{array}$ & GRP & \multicolumn{1}{c}{ Test run description } \\
\hline GRM-01 & 006 & $\begin{array}{l}\text { Fixed control nozzle area } \\
\text { Thrust step commands of increasing size }\end{array}$ \\
\hline GRM-02 & 019 & $\begin{array}{l}\text { Combustion chamber pressure of maximum } 80 \text { bar (nominal) } \\
\text { Control PMFR valve fixed, cut nozzle } \\
\text { Reignition trial: reignition after } 5 \text {-second pause without } \\
\text { propellant injection }\end{array}$ \\
\hline GRM-03 & 019 & $\begin{array}{l}\text { Command CC pressure of } 50 \text { bar } \\
\text { PMFR ramp command between } 0.9 \text { and } 0.18 \mathrm{~kg} / \mathrm{s}\end{array}$ \\
\hline GRM-04 & 019 & $\begin{array}{l}\text { Command CC pressure of } 50 \text { bar } \\
\text { PMFR ramp command between } 0.9 \text { and } 0.0 \mathrm{~kg} / \mathrm{s}\end{array}$ \\
\hline GRM-05 & 019 & $\begin{array}{l}\text { Command CC pressure of } 50 \text { bar } \\
\text { Control PMFR valve fixed } \\
\text { Step trial of the controllable injection head }\end{array}$ \\
\hline
\end{tabular}

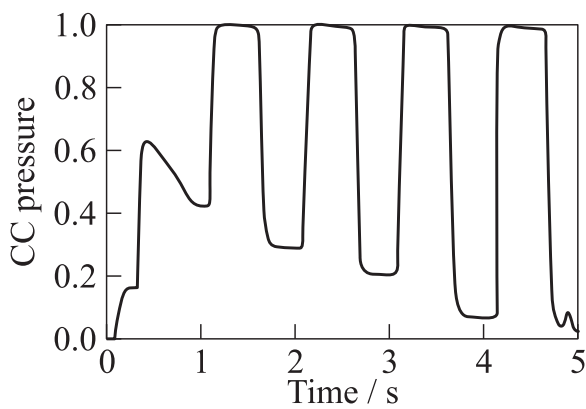

(a)

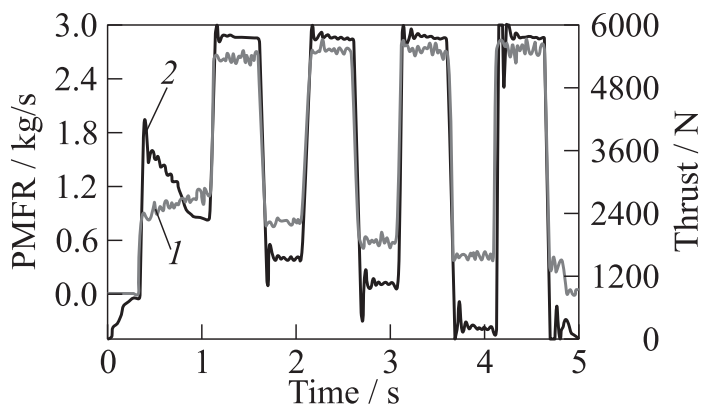

(b)

Figure 11 GRM-01 CC pressure (a); and PMFR (1) and thrust (2) (b) 
The chosen GRP for GRM-001 was GRP-006 (see Table 1) in order to confirm the performance characteristics of the motor. For the remainder trials, GRP-019 was used to maximize the operational life of the motor hardware for the trial series. GRP-019 has a nominal combustion temperature significantly lower than GRP-006.

\section{GRM-01}

GRM-01 consisted of a series of step commands with the maximum PMFR and thrust level corresponding to the fully open position of the control valve. Enough time was given between steps for the pressure to settle. The trial comprised of 4 positive and 4 negative steps for a total time duration of around $4.7 \mathrm{~s}$. The high thrust step level is kept constant and the low level thrust decreases for each step to evaluate the response of the GRM for step requests of increasing size.

Figure $11 a$ shows the normalized pressure in the CC. Since the pressure control valve was not active, the pressure in the CC is directly proportional to the amount of propellant being injected. The pressure shown has been normalized. The pressure peak at $t=0.4 \mathrm{~s}$ corresponds to the combustion start of the gel by the igniter in the CC. Figure $11 b$ shows the PMFR and thrust. The time delay between a PMFR increase and thrust increase in the $\mathrm{CC}$ is consistently lower than $5 \mathrm{~ms}$. The maximum thrust for this GRP and nozzle configuration is $5800 \mathrm{~N}$ at around $2.5 \mathrm{~kg} / \mathrm{s}$ of PMFR.

\section{GRM-02}

GRM-02 consisted of a constant command pressure of 50 bar and a PMFR reduction from 0.9 to $0.15 \mathrm{~kg} / \mathrm{s}$.

Figures $12 a$ to $12 d$ show the simulation (3) and testbench results (2) for GRM-02. The command pressure of 50 bar (see Fig. 12a) was achieved with a PMFR throttled down from 0.9 to $0.15 \mathrm{~kg} / \mathrm{s}$ (see Fig 12b). The combustion was stable until the end of the trial. The control nozzle effective area followed closely the results of the nominal simulation (see Fig. 12c) until the last $2 \mathrm{~s}$. The PMFR control valve position deviated from the nominal simulation (see Fig. $12 d$ ), with the deviation being larger for $t>4 \mathrm{~s}$. This explains the deviation from the nominal case of the control nozzle area. As a consequence of this trial, the feed forward term of the PMFR controller has been optimized.

\section{GRM-03}

GRM-03 consisted of two step commands of 80-bar nominal CC pressure, separated by $5 \mathrm{~s}$ of no propellant injection. 


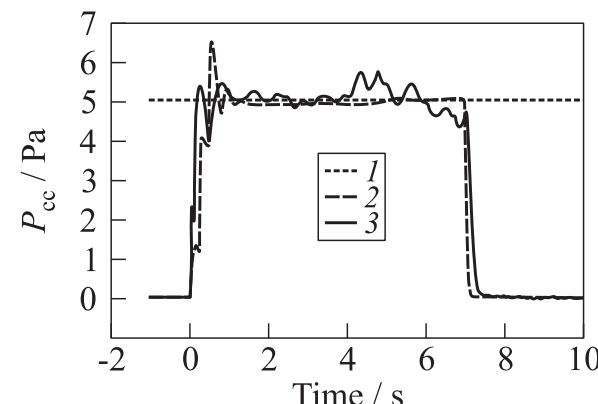

(a)

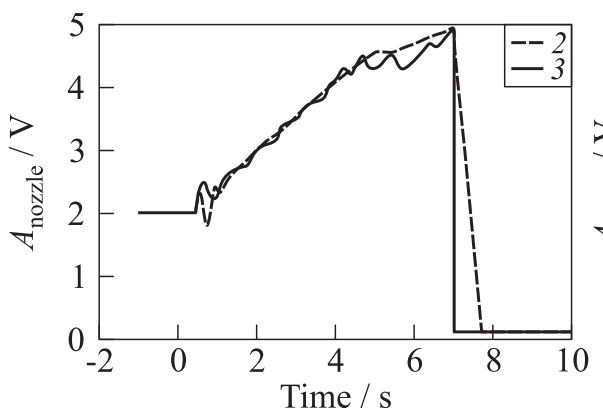

(c)

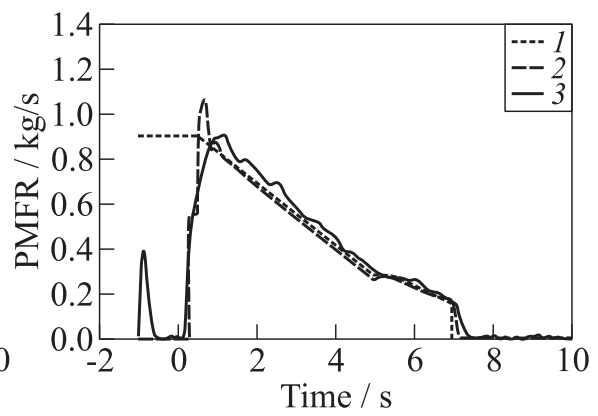

(b)

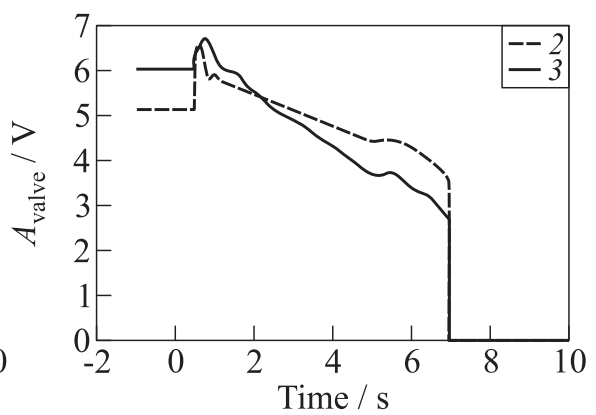

(d)

Figure 12 GRM-02 CC pressure (a), PMFR $(b)$, nozzle area $(c)$, and valve position $(d): 1$ - command; 2 - simulation; and 3 - trial

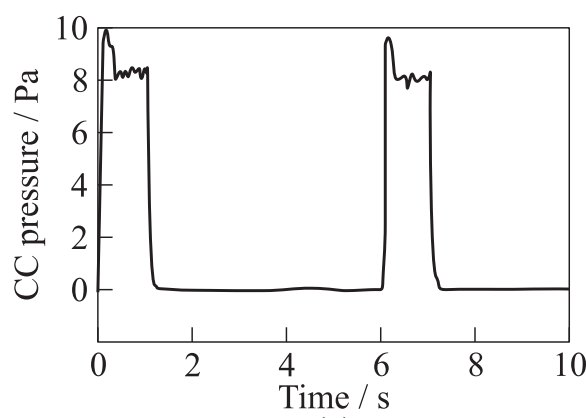

(a)

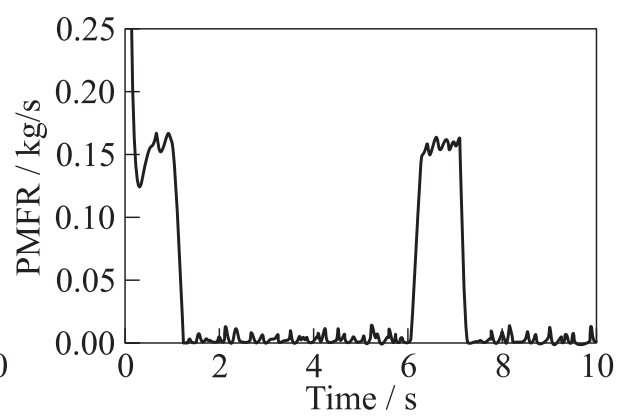

(b)

Figure 13 GRM-03 pressure $(a)$, and PMFR (b) 
The first ignition was $t=0 \mathrm{~s}$ and the PMFR was kept at a constant rate of $0.15 \mathrm{~kg} / \mathrm{s}$ (Fig. 13b) for $1 \mathrm{~s}$, after which the control valve was closed and the propellent injection stopped for $5 \mathrm{~s}$. Afterward, the valve was opened to the original position and the propellant injection resumed. Reignition was achieved through the means of a second reigniter placed in the injection head of the motor. The nominal pressure of 80 bar was reached for the two burns (see Fig. 13a) at PMFR approximately $0.15 \mathrm{~kg} / \mathrm{s}$ (see Fig. 13b).

\section{GRM-04}

GRM-04 consisted of a constant command pressure of 50 bar and a PMFR reduction from 0.2 to $0.0 \mathrm{~kg} / \mathrm{s}$. This trial had two objectives: firstly, to validate the updated PMFR controller; and secondly, to test the controllability of the Motor at very low thrust levels.

Figure 14 shows the simulation (3) and testbench results (2) for GRM-03. The control nozzle effective area followed closely the results of the nominal simu-

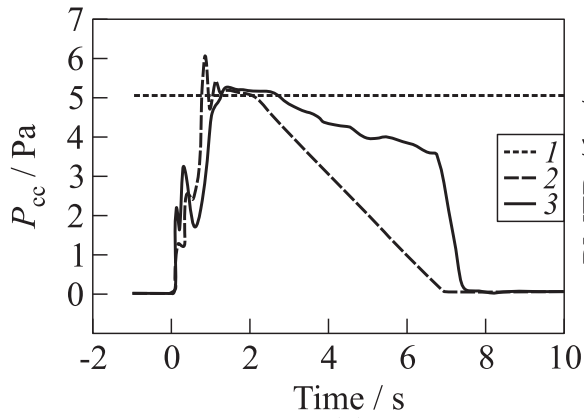

(a)

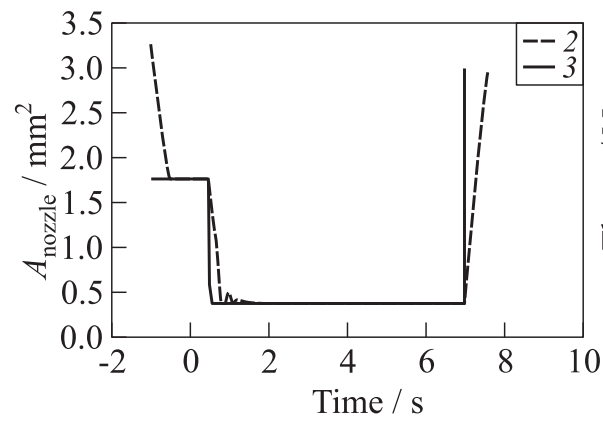

(c)

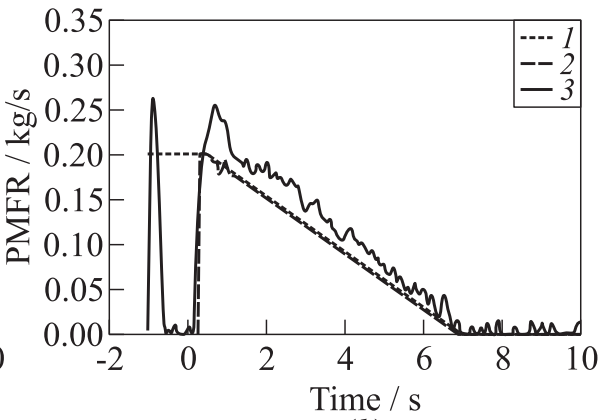

(b)

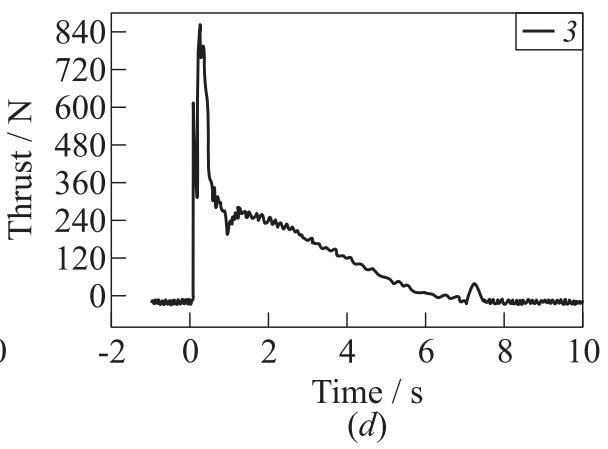

Figure 14 GRM-04 CC pressure $(a)$, PMFR $(b)$, nozzle area $(c)$, and thrust $(d)$ : 1 - command; 2 - simulation; and 3 - trial 
lation (see Fig. 14c) until the end of the trial. The PMFR control valve position deviated from the nominal simulation significantly less than for GRM-02 (see Fig. 14b). The command pressure of 50 bar was achieved until the point where the PMFR is insufficient to ensure that level of pressure even with the control nozzle at its smallest area position (see Fig. 14a). The thrust was effectively throttled down from 300 to $0 \mathrm{~N}$ (see Fig. $14 d$ ).

\section{GRM-05}

GRM-05 consisted of a constant command pressure of 50 bar and a series of thrust steps from 800 to $600 \mathrm{~N}$ and from 600 to $250 \mathrm{~N}$, and the back again to 600 and to $800 \mathrm{~N}$. The principal objective of the trial was the validation of the injector head controller. For this purpose, the PMFR control valve was fixed at a constant position.

Figure 15 shows the simulation (3) and testbench results (2) for GRM-04. The control nozzle effective area followed closely the results of the nominal sim-

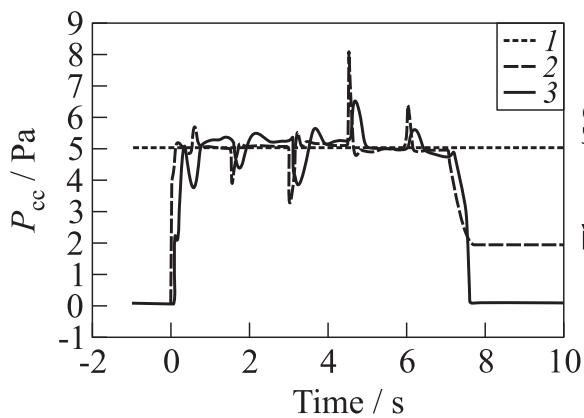

(a)

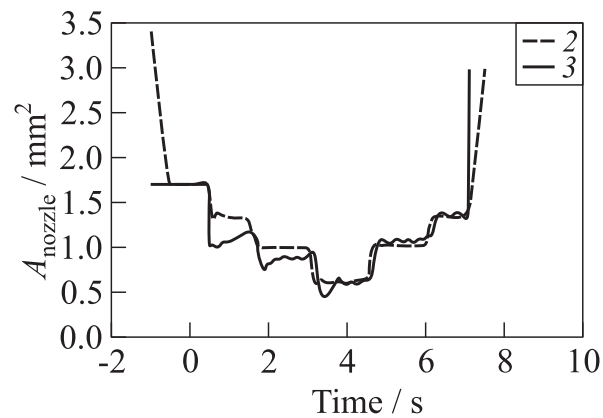

(c)

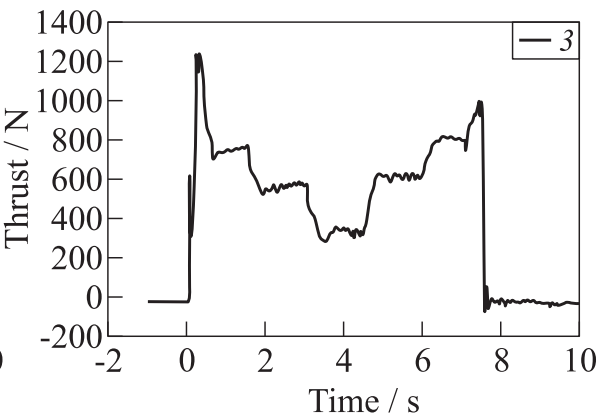

(b)

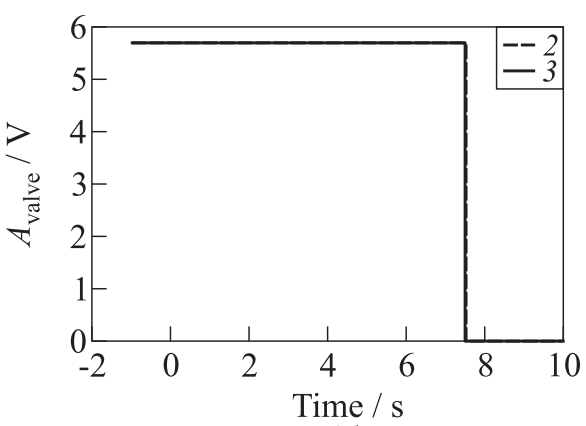

(d)

Figure 15 GRM-05 CC pressure $(a)$, thrust $(b)$, nozzle area $(c)$, and valve position $(d): 1$ - command; 2 - simulation; and 3 - trial 
ulation (see Fig. 15c) with a small deviation in the first half of the trial. The command pressure of 50 bar was achieved (see Fig. 15a). The analysis of the pressure in the CC shows that a faster response of the pressure loop controller is needed in order to ensure a smaller step error. The thrust was effectively throttled down and up in the series of four control steps (see Fig. 15d). Since for this trial the fuel control valve was kept at a fixed and constant position, the simulation and trial vale area overlap.

\section{APPLICATION OF GELLED PROPELLANT ROCKET MOTOR / GAS GENERATOR TECHNOLOGY}

This section is divided into three subsections. It begins with an overview of possible GRM and GGG applications. This overview is followed by a summary of possible applications for variable thrust rocket motors and DACS. The results of the theoretical computation for a specific DACS model are also presented and discussed in subsection 4.3.

\subsection{General Aspects}

For the following fields of application, BC's GRM/GGG technology offers particularly promising capabilities:

- replacement of LRM that operate on storable propellants, currently hydrazine, NTO, and IRFNA, for a thrust range of more than about 30-50 N. Such motors are in use for orbital transfer/insertion stages or upper stage motors of SRM launchers like VEGA, which need a final stage with at least thrust termination capability to achieve the correct burnout velocity;

- attitude control systems (ACS) for missiles that use laterally blowing jets. For such an application, a very high turndown ratio is essential to make efficient use of the propellant. This has been demonstrated by the tests with the HCCC;

- DACS for exoatmospheric vehicles that need high peak lateral acceleration and, consequently, high peak thrust but have also periods of nearly idle operation. The HCCC addresses this application as well;

- propulsion systems for missiles that provide initial boost and, after this, cruise thrust with the same GRM [20]; 
- missions that aim to land softly on the Moon or a larger asteroid, where no atmosphere supports deceleration, need a highly tunable propulsion system. This has to adapt the thrust level:

- to the reducing mass during descend; and

- to the reducing deceleration level as the lander approaches the surface with decreasing velocity;

- more specific information and some figures about such a lander propulsion concept are given in [21]; and

- propulsion systems for which safety, low hazard potential, low cost propellants, and environmental friendliness are the key requirements, e. g., for suborbital space tourism vehicles or sounding rockets [19].

More applications can be envisaged wherever rocket motors need to have a long burning time or a high turndown ratio, for example, roll control motors or attitude control motors for launchers without thrust vector control of the main engine.

\subsection{Variable Thrust Rocket Motors}

At the 5th EUCASS Conference [21], we presented a design concept of a GRM for trajectory insertion with shutoff or thrust adaptation capability and with figures for dimensions, performance and mass breakdown. The figures and information given in [21] and refined in [20] (Fig. 16) still hold and are confirmed by the recent results and the emerging state of the knowledge. This lightweight concept has a propellant mass fraction $m_{\text {Prop }} / m_{\text {tot }}=0.86$ (without thrust vector control or roll and attitude control systems). With proven GRP 006 as a conservative propellant, the stage has a stage specific impulse, i. e., the factor $I_{\text {tot,vac }} / m_{\text {tot,Stage }} \cong 2165 \mathrm{~N} \cdot \mathrm{s} / \mathrm{kg}$. This value is in the range of that of SRM boosters for sounding rockets of similar mass and also without thrust vector control or ancillary units (e.g., stage separation devices), which is estimated to be about $2100-2150 \mathrm{~m} / \mathrm{s}$. With more powerful GRP, $I_{\text {tot,vac }} / m_{\text {tot, Stage }}$ should be raised to more than $2400 \mathrm{~N} \cdot \mathrm{s} / \mathrm{kg}$ which is a good value for orbit insertion stages.

In the recent years, legislation and principles of operation require to deorbit man-made orbiting objects within a time of 25 years. Objects that are not destroyed upon reentry have to be deorbited in a controlled way and directed into remote ocean areas.

Here, a GRM has the advantage that the gas that was used to pressurize the GRP tank is available after the orbit insertion manoeuvre, even if the GRP is almost or totally used up. This gas can either be used to control the attitude of the stage during the deorbiting manoeuver or to support the deceleration 


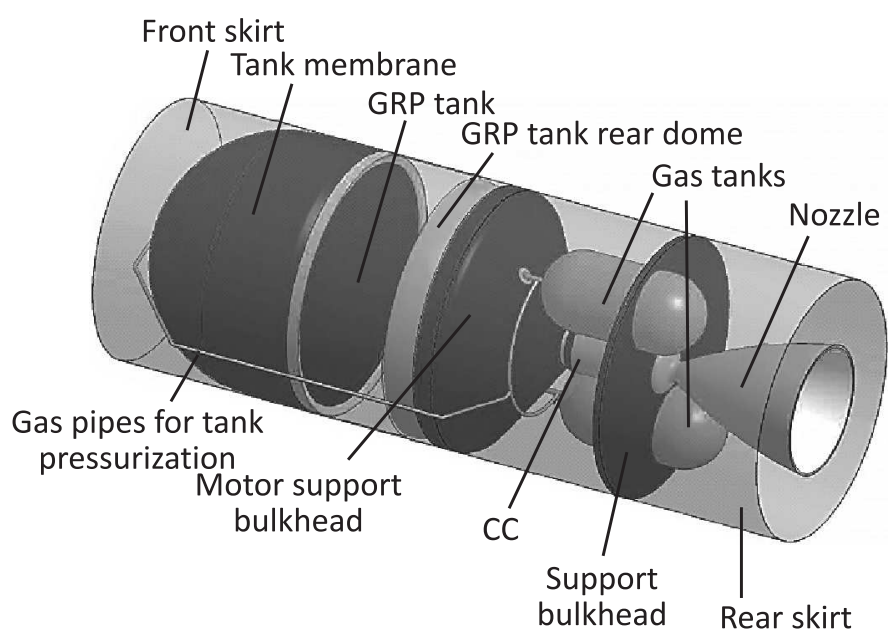

Figure 16 Sketch of the concept of an orbit insertion upper stage with a GRM. Stage mass: $1165 \mathrm{~kg}$; propellant mass: $1000 \mathrm{~kg}$; tank and body structures in carbon filament wound design; propellant tank with aluminum liner and membrane; and He inert gas tank pressurization

after the residual GRP has been used up. The stage of Fig. 16 has $7 \mathrm{~kg}$ of He in the tank which delivers an $I_{\text {spec }}=1719 \mathrm{~m} / \mathrm{s}$ upon expansion into vacuum through the main nozzle with $A_{e} / A^{*}=64$. The total impulse of $I_{\text {tot }}=12 \mathrm{kN} \cdot \mathrm{s}$ for $\mathrm{He}$ at $293 \mathrm{~K}$ is well enough for attitude control. If used for deceleration, the gas provides for the empty stage with a mass of $m=165 \mathrm{~kg}$ a velocity decrement of $\Delta v=I_{\text {tot }} / m=73 \mathrm{~m} / \mathrm{s}$. This is well below the numbers given in [22] for the controlled reentry of objects in circular orbits beyond $600 \mathrm{~km}$, but can compensate for example uncertainties in the estimation of the mass of residual propellant.

\subsection{Divert and Attitude Control Systems}

Attitude control systems and divert control systems (DCS) use impulse force to control the attitude (pitch, yaw, and roll) of a vehicle or to change its trajectory. Systems that provide both features are DACS.

Attitude control systems are used in space launchers, preferably for the upper stages, which operate under conditions where aerodynamic control is not really effective. Figure $17 a$ shows a principle concept of such a system with a GGG, designated gel ACS (G-ACS). Other applications are found in missile applications either for control at high flight altitude, or to improve agility in the endgame, or to turn the missile immediately after launch. 


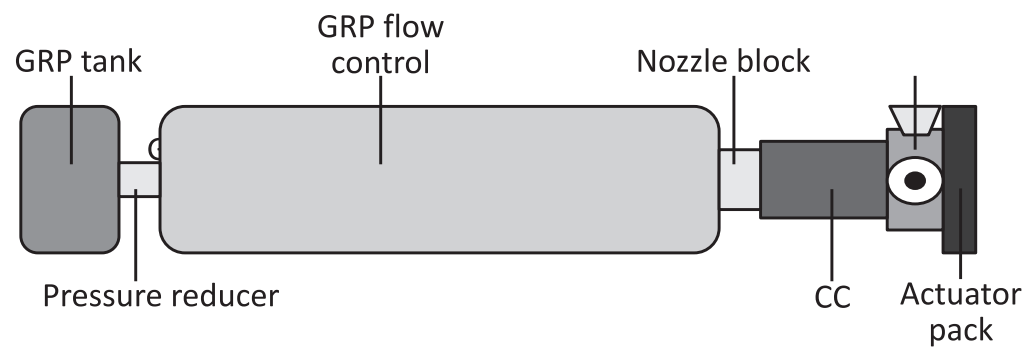

(a)

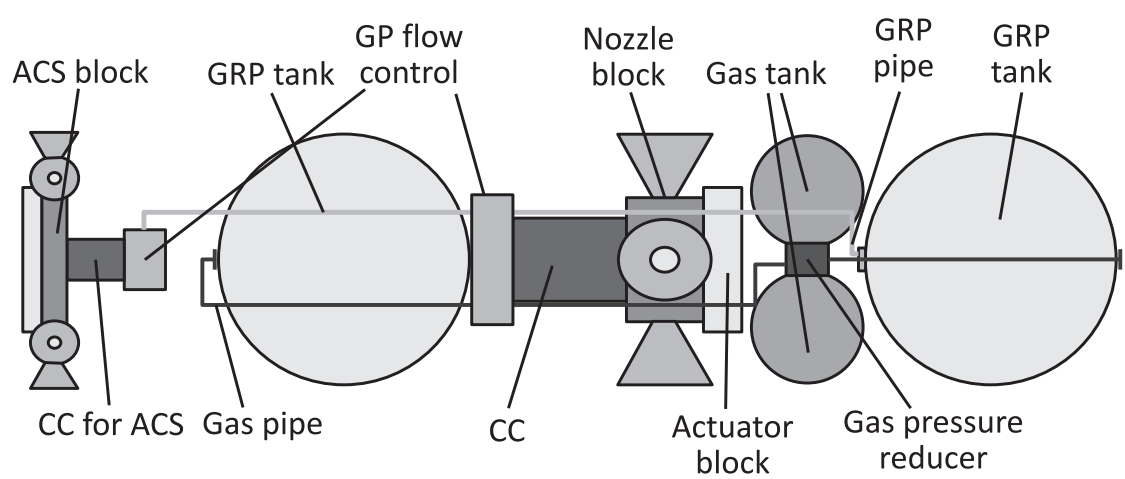

(b)

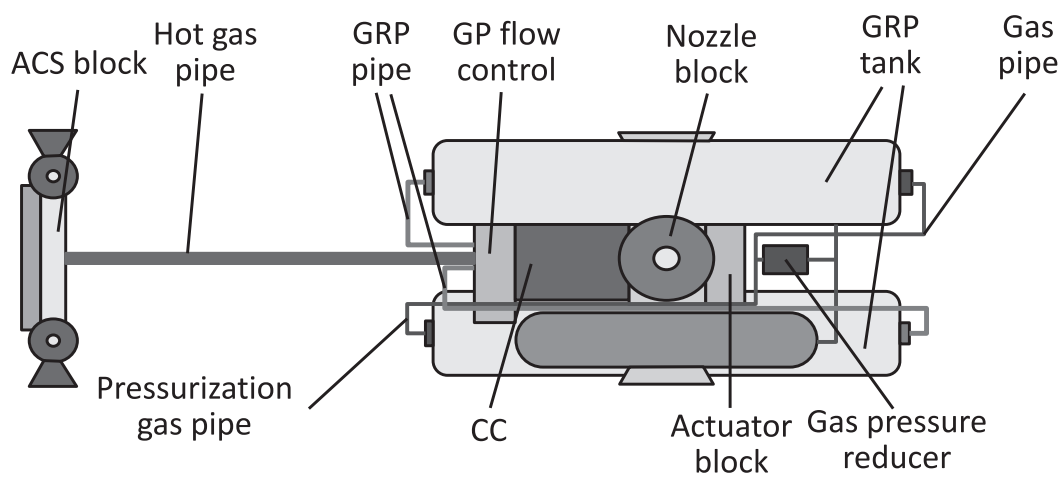

(c)

Figure 17 Concept of a G-ACS system with inert gas tank pressurization and HCCC connected to a nozzle block with three thrusters $(a)$; G-DACS with separate GGG for DCS and ACS nozzles, membane propellant tanks, and inert gas propellant tank pessurization (b); and G-DACS with central GGG for DCS and ACS nozzles, piston propellant tanks, and inert gas propellant tank pressurization $(c)$ 
The DACS are used to control the trajectory and the attitude of vehicles that travel outside of the atmosphere. Mostly, the DCS thrusters are arranged around the center of gravity whereas the ACS systems are situated near the periphery. Driven by the respective objectives, the maximum thrust level of a DCS needs to be significantly higher than that of the ACS. One possible solution is to use two HCCC that are sized for the specific thrust, i. e., gas mass flow requirements of the DCS and ACS thrusters. It illustrates such a principle concept of a gel DACS (G-DACS) with separate HCCC for the DCS and ACS nozzle blocks [23].

If the arrangement of the components inside the space vehicle allows integrating a direct hot gas pipe between the HCCC and the ACS block, this arrangement has the advantage that it reduces the propellant consumption in nearly idle operation compared to the system of Fig. $17 b$ with two separate HCCC. Figure $17 c$ shows a principal sketch of such a DACS arrangement. In the end, trade-offs on system design level have to weigh the advantages, shortcomings, restrictions, and benefits of different solutions. From the point of view of the hot gas supply, the integration and thermal insulation of a hot gas duct may be less expensive than the use of a second HCCC for the ACS block.

Some of the ACS and DACS applications have foreseeably very short operation times of few seconds, for example, DCS that have just to provide a small trajectory correction to secure a direct hit on a target, or ACS that point a missile into the flight direction immediately after launch. For such short operation times of few seconds, the trade-off between efficiency of propellant use and simplicity of design and operation mostly goes to the favour of simplicity. This means to use either:

- a continuously operating SP GG (SGG) with a valve system, or

- multiple impulse thrusters on the circumference of a rolling missile that operate when they point into the correct azimuthal direction.

The array of multiple impulse thrusters works safely but has an extremely poor volumetric efficiency and a very poor ratio of propellant mass to total mass. For very short operation times, the shortcoming of limited mass flow controllability of a SGG may be compensated by the simple design, i.e., the identity of propellant tank and $\mathrm{CC}$ which needs no ancillary components besides an ignition and safety device. And for short operation times, the mass of the internal thermal heat shield of a SGG is limited.

For continuously operating systems that operate only for few seconds, the heating scenario of the valve assembly is highly transient due to the thermal inertia of the structures. Consequently, for a very short operation time, the valve system can be subjected to temperatures that are higher than the melting or decomposition temperature of the structure materials. This reduces the engineering challenge in terms of material selection and design methods. 
Systems that envisage long operation times, say, of more than $10 \mathrm{~s}$, are

- ACS of upper stages of space launchers, or

- DACS of intercept vehicles that engage oncoming ballistic warheads in exoatmospheric space.

These systems have not only long operation times but as well highly varying thrust demand because the intensity of trajectory correction manoeuvres varies significantly over time. Whereas ACS and DACS are different by nature, they have in common that a GGG with an HCCC is an ideal solution for a continuously operating system. Specifics of each of these systems are:

(1) the ACS of an upper stage of a launcher has to operate at least as long as the stage itself. In addition, the ACS has to compensate disturbances generated by stage separation or ignition actions. One can expect some demand on peak thrust, whereas over most of the time, the thrust demand will be much lower. Along the time of operation, a highly variable, adapted PMFR will generate significant savings of propellant; and

(2) during the mission of an intercept vehicle most of the flight time needs just ACS action to stabilize the vehicle in the exoatmospheric ambience. High thrust phases of the DCS, for example during the end-game, are comparatively short. Here as well, along the time of operation a highly variable PMFR will generate significant savings of propellant.

For both applications, it makes sense to use a GGG with HCCC that burns just the amount of propellant that is needed in a specific situation. An additional advantage of a GGG is the capability to rapidly increase the gas production. Figure 17 shows that even for a straightforward system with fixed nozzle crosssection area that had not been optimized for rapid changes of gas production, the delay between a change in PMFR and GGG pressure is just about $5 \mathrm{~ms}$.

A special challenge in case of long operation times is the design of the valve/nozzle system and the material selection. We cannot expect that the thermal inertia and heat sink capability of the structure materials will prevent significant degradation or even destruction of the heated parts if they are subjected to extreme temperatures, say, higher than the melting point or some other temperature limit driven by required residual mechanical strength. In contrast, parts with a high ratio of wetted surface to volume will, at least partly, reach almost adiabatic temperature levels. Careful aerothermal modeling, using fluidstructure coupling, yields information about what maximum gas temperature level can be sustained for the foreseen time and conditions of operation.

In any case, the outcome will be that the ballistic performance of the propellant, i. e., $I_{\text {spec }}$, has to be adapted to the thermal sustainability of the structures, 
say, the maximum tolerable $T_{c}$. High-performance SP are not only too hot, hav$\operatorname{ing} T_{c}$ of up to $3600 \mathrm{~K}$, but the aluminum oxide particles will damage and block the valve system. Aluminum-free composite propellants are particle-free, but have $T_{c}$ up to and above $3000 \mathrm{~K}$. For long operation times, this is still too much even for parts made of refractory metals.

Independent of the nature of the propellant, either it is solid, or liquid, or gelled, $I_{\text {spec }}$ has to be reduced compared to the maximum achievable textbook values because $T_{c}$ has to be limited.

A specific advantage of gelled propellants is that $T_{c}$ can be readily adapted to the tolerable limit by just composing an appropriate blend of propellants, additives, and gelling agents. If the tolerable $T_{c}$ is about $2000 \mathrm{~K}$, say, a temperature level that is tolerated for long operation times by some alloys or fibre reinforced ceramics, GRP 006 which has a wide range of burning pressure and produces no deposits is a good solution. For GGG that have to drive more complex machinery, GRP 007, GRP 008, and GRP 010 with very low $T_{c}$ are a good choice. If we disregard GRP that produce a tangible amount of particles or corrosive components, the current limit is represented by GRP 006 with $I_{\text {spec,max }}$ of about $2250 \mathrm{~m} / \mathrm{s}$ (about $230 \mathrm{~s}$ in US units) for $70: 1$ expansion into atmosphere or $2500 \mathrm{~m} / \mathrm{s}$ (about $255 \mathrm{~s}$ in US units) for expansion into vacuum with a nozzle area ratio $A_{e} / A^{*}$ of about 60 . The associated $T_{c}$ is about $2000 \mathrm{~K}$.

The design of the GG follows that of the HCCC which is shown in Fig. $17 a$ and described in detail in [21]. One of the key elements, the controllable nozzle throat cross section area $A^{*}$, is represented in an ACS or DACS by the jointly acting nozzle throat cross-section areas $\sum A_{i}^{*}$ for an ACS or DCS, or $\sum\left(A_{i}^{*}+A_{j}^{*}\right)$ for a DACS with one central GGG. Here, $A_{i}^{*}$ designates the thrusters of an ACS or DCS, or the main thrusters of a DACS with central GGG, and $A_{j}^{*}$ designates the much smaller ACS thrusters of this DACS. An independent actuation of the HCCC and the individual $A_{i}^{*}+A_{j}^{*}$ of the thrusters allows to adapt the total $A_{\mathrm{tot}}^{*}=\sum A_{i}^{*}$ for ACS and DCS or $A_{\mathrm{tot}}^{*}=\sum\left(A_{i}^{*}+A_{j}^{*}\right)$ for a DACS with a central GGG in that way that

- the overall force vectors $\mathfrak{F}_{\mathrm{DCS}}=\sum \mathfrak{F}_{i}$ and $\mathfrak{F}_{\mathrm{ACS}}=\sum \mathfrak{F}_{j}$ can be achieved by the coordinated actuation of the nozzle valves which distribute the total gas mass flow to the individual nozzles; and

- the necessary PMFR to obtain $\sum \mathfrak{F}_{i}+\sum \mathfrak{F}_{j}$ is controlled by joint action of the propellant main valve and the variable injector elements. At low PMFR, the closing of an appropriate number of the variable injector elements secures a sufficiently high PMFR through the open injector elements to assure good spraying behavior.

In the following, some numbers give an idea about such a DACS and its operation: 
- the HCCC in [24] can operate with a maximum PMFR of $2.5 \mathrm{~kg} / \mathrm{s}$ and with a minimum PMFR of $0.05 \mathrm{~kg} / \mathrm{s}$. The maximum PMFR is achieved with 18 open injector elements at $p_{T}-p_{c} \sim 5 \mathrm{MPa}$ and the minimum PMFR is achieved with two open injector elements at $p_{T}-p_{c} \sim 6.4 \mathrm{MPa}$; upon approaching the minimum PMFR towards the end of the test, $A^{*}$ of the variable nozzle had reached its technical minimum and $p_{c}$ had dropped to about 3.6 $\mathrm{MPa}$ while $p_{T}$ retained its value of $10 \mathrm{MPa}$;

- a maximum PMFR of $2.5 \mathrm{~kg} / \mathrm{s}$ using GRP 006 can produce a total thrust of $6.25 \mathrm{kN}$ at expansion into vacuum. For sure, in a DACS, some deductions have to be taken into account due to losses in the nozzle/valve blocks and the hot gas pipe to the ACS block;

- in the worst case, the orientation of the required $\mathfrak{F}_{\text {DCS }}$ is in the midst of the orientations of the next two cartesian DCS nozzles. In this case, the ideal maximum $\left|\mathfrak{F}_{\mathrm{DCS}}\right|=\left(F_{i, 1}^{2}+F_{i, 2}^{2}\right)^{1 / 2}=(2 \cdot 9.77)^{1 / 2}=4.42 \mathrm{kN}$;

- at a minimum PMFR of $0.05 \mathrm{~kg} / \mathrm{s}$ as it was achieved in the test, the ACS thrusters can produce a total thrust of $125 \mathrm{~N}$ if losses are neglected;

- in the worst case, if the orientation of the required $\mathfrak{F}_{\text {ACS }}$ is in the midst of the orientations of the next two cartesian ACS nozzles, the ideal maximum $\left|\mathfrak{F}_{\mathrm{ACS}}\right|=\left(F_{j, 1}^{2}+F_{j, 2}^{2}\right)^{1 / 2}=88 \mathrm{~N}$;

- if the required $\mathfrak{F}_{\text {ACS }}$ is lower than this value, the excess gas can be vented by an appropriate opening of two opposite ACS nozzles that creates no residual thrust beyond that level which is required; and

- the gas production of the HCCC can be ramped up very rapidly, currently within $0.1 \mathrm{~s}$. Some manoeuvres require a faster action time, for example, the DCS operation in the end-game when a ballistic warhead has to be hit directly. But the time interval when such rapid high thrust manoeuvres are required can often be predicted. Hence, a timely ramp-up of the HCCC gas production will be possible in many cases. As far as not yet all gas is needed for residual thrust generation, the excess gas can be vented by an appropriate opening of two opposite DCS nozzles that creates no residual thrust beyond that level which is required.

The following generic example can be calculated: A DACS should provide for the following time intervals the following residual thrust levels:

(1) full DCS thrust of $4 \mathrm{kN}$ in any direction for $3 \mathrm{~s}$;

(2) limited DCS thrust of $2 \mathrm{kN}$ in any direction for $5 \mathrm{~s}$;

(3) full ACS thrust of $250 \mathrm{~N}$ in any direction for $3 \mathrm{~s}$; 
(4) limited ACS thrust of $150 \mathrm{~N}$ for $5 \mathrm{~s}$;

(5) low ACS thrust of $50 \mathrm{~N}$ in any direction for $60 \mathrm{~s}$; and

(6) no ACS or DCS operation for $60 \mathrm{~s}$.

The associated propellant consumption for ideal operation in vacuum, without losses, and with $\mathfrak{F}_{\text {DCS }}$ and $\mathfrak{F}_{\text {ACS }}$ pointing into the worst direction is:

(1) $6.79 \mathrm{~kg}$ for $2 \cdot 2.83 \mathrm{kN} \cdot 3 \mathrm{~s}$;

(2) $5.65 \mathrm{~kg}$ for $2 \cdot 1.41 \mathrm{kN} \cdot 5 \mathrm{~s}$;

(3) $0.42 \mathrm{~kg}$ for $2 \cdot 177 \mathrm{~N} \cdot 3 \mathrm{~s}$;

(4) $0.42 \mathrm{~kg}$ for $2 \cdot 106 \mathrm{~N} \cdot 5 \mathrm{~s}$;

(5) $1.70 \mathrm{~kg}$ for $2 \cdot 35 \mathrm{~N} \cdot 60 \mathrm{~s}+1.30 \mathrm{~kg}$ to be vented over $60 \mathrm{~s}$ if the average $\mathfrak{F}_{\mathrm{ACS}}=50 \mathrm{~N}$; and

(6) $3.00 \mathrm{~kg}$ for $60 \mathrm{~s}$ of idle operation with a minimum PMFR of $0.05 \mathrm{~kg} / \mathrm{s}$.

The total propellant consumption for this operation cycle without losses amounts to $19.3 \mathrm{~kg}$. The propellant not used for direct thrust generation amounts to $4.3 \mathrm{~kg}$, which represents an idle operation propellant fraction of $22.3 \%$.

If, for comparison, an SGG is used, the fact can be used that the burning rate $r_{b}$ of most SP increases with $p_{c}$. The relation can be approximated by Vieille's law. Table 3 gives some values.

One can see that a propellant with an $n<0.5$ is by no way appropriate for such an application because the high maximum pressure needed requires a corresponding high structural mass. But whereas the $p_{c} / p_{c, 0}$ for $n \geq 0.5$ look not unrealistic at the first glance, one has to take into account that

- the minimum $p_{c}$ for stable combustion has to be very low, say, $p_{c}<$ $0.5 \mathrm{MPa}$, to achieve an $r_{b} / r_{b, 0}$ of 10 while not exceeding a reasonable $p_{c, \text { max }}$ of about $20 \mathrm{MPa}$. Even then $n>0.6$ is needed;

- because $n$ is usually not constant over the entire pressure range, the average $n$ needs to keep a little bit away from the value 1 which indicates the boundary of instable combustion. Hence, $n=0.8$ is a reasonable effective limit for $n$; and
Table 3 Relation of pressure dependent on the pressure exponent $n$ at SP burning rate $r_{b} / r_{b, 0}=10$

\begin{tabular}{cc}
\hline$n$ & $p_{c} / p_{c, 0}$ \\
\hline 0.4 & 316 \\
0.5 & 100 \\
0.6 & 46.4 \\
0.7 & 26.8 \\
0.8 & 17.8 \\
\hline
\end{tabular}


- the ramp-up of gas production is slower than that of a GGG. Especially at the end of the operation time, when the void volume in the CC of a solid GG is high, the gas dynamic inertia of the $p_{c}$ control stands against a fast ramp-up of gas production. When the valves reduce $A^{*}$ to increase $p_{c}$ and by this $r_{b}$, the gas has first to pressurize the empty volume of the SGG in order to increase the gas production before the gas stream that is associated to a constant operation condition can be supplied to the DSC and ACS blocks.

For the following estimation of the propellant consumption of an S-DACS that covers the same operation phases $1-6$ as the G-DACS outlined above, let us assume:

- the same maximum $T_{c} \sim 2000 \mathrm{~K}$ that can be tolerated by the valve/nozzle systems. This leads to about the same $I_{\text {spec }}$ and we use, therefore, equally $I_{\text {spec }, \text { vac }}=2500 \mathrm{~m} / \mathrm{s}$;

- the losses are not taken into account. This does not affect the value of the comparison because the valve/nozzle systems of a G-DACS and an S-DACS are similar; and

- a burning rate turndown ratio of 10 . Whereas the maximum PMFR needs to be $2.4 \mathrm{~kg} / \mathrm{s}$, the minimum PMFR is $0.24 \mathrm{~kg} / \mathrm{s}$.

For the S-DACS, the associated propellant consumption for ideal operation in vacuum, without losses, and with $\mathfrak{F}_{\text {DCS }}$ and $\mathfrak{F}_{\text {ACS }}$ pointing into the worst direction is:

(1) $6.79 \mathrm{~kg}$ for $2 \cdot 2.83 \mathrm{kN} \cdot 3 \mathrm{~s}$;

(2) $5.65 \mathrm{~kg}$ for $2 \cdot 1.41 \mathrm{kN} \cdot 5 \mathrm{~s}$;

(3) $0.42 \mathrm{~kg}$ for $2 \cdot 177 \mathrm{~N} \cdot 3 \mathrm{~s}$;

(4) $0.42 \mathrm{~kg}$ for $2 \cdot 106 \mathrm{~N} \cdot 5 \mathrm{~s}$;

(5) $1.70 \mathrm{~kg}$ for $2 \cdot 35 \mathrm{~N} \cdot 60 \mathrm{~s}+12.7 \mathrm{~kg}$ to be vented over $60 \mathrm{~s}$ if the average $\mathfrak{F}_{\mathrm{ACS}}=50 \mathrm{~N}$; and

(6) $14.4 \mathrm{~kg}$ for $60 \mathrm{~s}$ of idle operation with a minimum PMFR of $0.24 \mathrm{~kg} / \mathrm{s}$.

The total propellant consumption for this operation cycle without losses amounts to $42.1 \mathrm{~kg}$. The propellant not used for direct thrust generation amounts to $27.1 \mathrm{~kg}$.

This exemplary comparison shows that the G-DACS needs just $46 \%$ of the propellant of the assumed S-DACS, even as the SGG should have a wide burning rate turndown ratio of 10 . The high propellant consumption of the S-DACS in 
idle phases can be overcome by using a set of SP cartridges with different high and low propellant yield and ignite these upon request. Shortcomings of this method are:

- increased complexity of the system, particularly, due to the number of ignition chains, pulse separation devices, and interfaces; and

- the number of high-yield cartridges limits the number of high-thrust operation cycles

Of course, propellant consumption is not the only relevant parameter of a system. The DCS and ACS blocks make no difference because these just distribute the gas mass flow delivered by the GG. The critical issue for both variants is the thermal management:

- for the SGG, the identity of tank and CC is critical in so far, as the whole $\mathrm{CC}$ surface has to be protected against heating by the hot gas if the grain is a cigarette burner, which is almost the only solution for long operation times. Hence, the internal thermal insulation of the $\mathrm{CC}$ may become a mass driver. In addition, temperature sensitive materials like Al-alloys or fibre reinforced resin are critical and steel or Ti should be preferred;

- for the GGG, the hot part is just the CC, while by the far larger tank can be kept at ambient temperature. This allows selecting the tank materials only for strength and low mass at ambient temperature. The comparatively small CC has to withstand the same temperature as the DCS and ACS blocks. The temperature sensitive part is the injector head and careful thermal management is needed to secure correct operation over such long burning times; and

- the SP cartridges cannot be arranged as liberally as the gelled propellant and pressurization gas tanks.

Without giving detailed concepts, we notice that the SGG needs the heavier structures while the GGG needs a gas pressurization system and the CC. As outlined above, the trade-off is in favor to SGG for very short operation times, but definitely in favor of a GGG for longer operation times.

\section{SUMMARY AND OUTLOOK}

Gel propulsion systems have the potential to combine easy throttleability with easy handling and storage characteristics. Detailed $\mathrm{R}+\mathrm{T}$ development work was conducted within the GGPT Program to get a deeper understanding of rheological, flow, spray, combustion, and combustor process characteristics. Suitable monopropellant or fuel and oxidizer gels can be fed and sprayed with suitable 
injectors. With suitable monopropellant gels, compact combustor processes even in small model combustors can be realized.

The conducted concept studies show that the GRM technology allows building lightweight rocket motor stages with controllable thrust, low hazard potential, and easy handling, transport, and storage properties. In order to allow a couple of pulses, a reignition capability is under development. An ideal application is also for landers on larger asteroids, moons, or planets without atmosphere [21].

Because of the demonstrated very high turndown ratio of a GRM with a HCCC, this technology provides a very good GG solution for continuously operating ACS and DACS. The very high turndown ratio minimizes the propellant consumption at the lowest operational point. Furthermore, suitable gel propellant compositions allow tailoring the combustion temperature of the GRP to temperature limits that the mechanical part can tolerate for the given mission profile.

Current activities aim to improve further the functional and performance parameters. The main goals are:

- to increase $I_{\text {spec }}$ and $I_{\text {spec,vol }}$ of the monopropellant system;

- to develop a reignition capability; and

- to improve the capability for long time operation and to scale the combustor process.

To sum up, despite the realization of a good understanding of gel propulsion relevant processes and of a profound technology base within the GGPT Program, there are still gaps to close.

\section{ACKNOWLEDGMENTS}

We highly appreciate the continuous support of the German MoD's BAAINBw and the exceptionally fruitful co-operation with the Fraunhofer Institute for Chemical Technology (ICT) and the Bundeswehr Technical Center for Weapons and Ammunition (WTD 91). The authors would also like to thank their colleagues from Fraunhofer ICT for the development and production of several gel propellants. Furthermore, they acknowledge the support by the teams for the conduction of the experiments at M11 test complex of DLR and at BC.

\section{REFERENCES}

1. Natan, B., and S. Rahimi. 2002. The status of gel propellants in year 2000. Combustion of energetic materials. Eds. K. K. Kuo and L. T. DeLuca. Begell House, USA. 172-194. 
2. Ciezki, H. K., K. W. Naumann, and V. Weiser. 2010. Status of gel propulsion in the year 2010 with a special view on German activities. Deutscher Luft- und Raumfahrtkongress 2010. Hamburg, Germany.

3. Sackheim, R. L., and R. K. Masse. 2014. Green propulsion advancement: Challenging the maturity of monopropellant hydrazine. J. Propul. Power 30(2):265-276.

4. Schmid, K., J. Ramsel, K.W. Naumann, R. Stierle, and V. Weiser. 2012. Raketenmotore mit Gel-Treibstoffen - Stand der Technologie bei Bayern-Chemie. Deutscher Luft- und Raumfahrtkongress 2012. Berlin, Germany.

5. Madlener, K., and H. K. Ciezki. 2009. Some aspects of rheological and flow characteristics of gel propellants with regard to propulsion application. AIAA Paper No. 2009-5240.

6. Madlener, K., and H.K. Ciezki. 2005. Theoretical investigation of the flow behavior of gelled propellants of the extended Herschel-Bulkley type. 1st European Conference on Aerospace Sciences. Moscow, Russia.

7. Negri, M., M. Redaelli, and H. K. Ciezki. 2012. Recent results on thread formation with an impinging jet injector. AIAA Paper No. 2012-3967.

8. Negri, M., M. Redaelli, H. K. Ciezki, and S. Schlechtriem. 2012. Influence of relaxation time on the spray behavior of viscoelastic fluids with an impinging jet injector. 61st German Aerospace Congress (Deutscher Luft- und Raumfahrtkongress) 2012. Berlin, Germany.

9. Negri, M. 2013. Breakup behavior of non-Newtonian fluids with threads and droplets formation in impinging jet injectors. Stuttgart, Germany: University of Stuttgart. PhD Thesis.

10. Madlener, K., and H. K. Ciezki. 2012. Estimation of flow properties of gelled propellants with regard to propulsion systems. J. Propul. Power 28:113-121.

11. Negri, M., and H.K. Ciezki. 2015. Combustion of gelled propellants containing micro and nano-sized aluminum particles. J. Propul. Power 31(1):400-407.

12. Negri, M., H.K. Ciezki, and S. Schlechtriem. 2013. Spray behavior of non-Newtonian fluids: Correlation between rheological measurements and droplets/threads formation. Progress in propulsion physics. Eds. L. DeLuca, C. Bonnal, O. Haidn, and S. Frolov, EUCASS advances in aerospace sciences book ser. TORUS PRESS - EDP Sciences. 4:271-290.

13. Von Kampen, J., F. Alberio, and H. K. Ciezki. 2007. Spray and combustion characteristics of aluminized gelled propellants with an impinging jet injector. Aerosp. Sci. Technol. 11:77-83.

14. Gafni, G., A. Kuznetsov, and B. Natan. 2015. Experimental investigation of an aluminized gel fuel ramjet combustor. Chemical rocket propulsion - a comprehensive survey of energetic materials. Eds. L. DeLuca, T. Shimada, V.P. Sinditskii, and M. Calabro. Springer Verlag. Ch. 3. Paper No. 12.

15. Balas, S., and B. Natan. 2016. Boron oxide condensation in a hydrocarbon-boron gel fuel ramjet. J. Propul. Power 32(4):967-974.

16. Ciezki, H. K., and M. Negri. 2013. Overview on gel propulsion activities at DLR Institute of Space Propulsion. European Conference on Aerospace Sciences. Munich, Germany. Paper No. 267. 
17. Ciezki, H. K., M. Negri, and A. Gernoth. 2015. Advanced liquid and gelled propellants for rocket and ramjet propulsion. Int. J. Energetic Materials Chemical Propulsion 14(2):85-123.

18. Stierle, R., K. Schmid, J. Ramsel, and K. W. Naumann. 2011. Free-flight demonstration of the gelled propellant rocket motor of MBDA-Bayern-Chemie. 4th European Conference for Aeronautics and Space Sciences. St. Petersburg, Russia.

19. Naumann, K. W., H. K. Ciezki, R. Stierle, K. Schmid, and J. Ramsel. 2011. Rocket propulsion with gelled propellants for sounding rockets. 20th ESA Symposium on European Rocket and Ballon Programmes and Related Research. Hyères, France.

20. Naumann, K.W., J. Ramsel, P. Caldas-Pinto, H. Niedermaier, S. Scheutzow, C. M. Rienäcker, and A. Thumann. 2014. Gelled green propellant rocket motor and gas generator technology at Bayern-Chemie - status and applications for space systems. AIAA Paper No. 2014-3796.

21. Naumann, K.W., J. Ramsel, K. Schmid, P. Caldas-Pinto, H. Niedermaier, and A. Thumann. 2013. Application of green propulsion systems using rocket motors and gas generators with gelled propellants. 5th European Conference for Aeronautics and Space Sciences. Munich, Germany.

22. Janovsky, R., M. Kassebom, H. Lübberstedt, O. Romberg, H. Burkhardt, M. Sippel, G. Krülle, and B. Fritsche. 2002. End-of-life de-orbiting strategies for satellites. Deutscher Luft-und Raumfahrtkongress 2002. Stuttgart, Germany.

23. Naumann, K. W., J. Ramsel, H. Niedermaier, P. Caldas-Pinto, N. Hopfe, S. Scheutzow, C. M. Riemäcker, and A. Thumann. 2014. The application of rocket motors and gas generators with gelled propellants for BMD interceptors. AAAF 10th Conference (International) on Missile Defence. Mainz, Germany.

24. Caldas Pinto, P., J. Ramsel, S. Scheutzow, K.W. Naumann, A. Thumann, and G. Kurth. 2015. Control characteristics of a gel propellant throttleable rocket motor. 6th European Conference for Aeronautics and Space Sciences. Krakow, Poland. 